Schindler, J.; Kupfer, S.; Ryan, A. A.; Flanagan, K. J.; Dietzek, B.; Senge, M. O. (2018):

Sterically induced distortions of nickel(II) porphyrins - Comprehensive investigation by DFT calculations and resonance Raman spectroscopy.

Coordination Chemistry Reviews 360, 1-16. doi: 10.1016/j.ccr.2017.12.014

\title{
Sterically Induced Distortions of Nickel(II) Porphyrins - Comprehensive Investigation by DFT Calculations and Resonance Raman Spectroscopy
}

Julian Schindler, ${ }^{a, b}$ Stephan Kupfer, ${ }^{a}$ Aoife A. Ryan,, ${ }^{c}$ Keith J. Flanagan, ${ }^{c}$ Mathias O. Senge, ${ }^{c}$ and Benjamin Dietzek*,a,b

Supporting Information available.

a Institute of Physical Chemistry and Abbe Center of Photonics, Friedrich Schiller University Jena, Helmholtzweg 4, 07743 Jena, Germany. Phone: +49 3641 206332; Fax: +49 3641 206299; E-mail: benjamin.dietzek@leibniz-ipht.de

b Leibniz Institute of Photonic Technology Jena (IPHT), Department Functional Interfaces, Albert-Einstein-Straße 9, 07745 Jena, Germany.

c School of Chemistry, SFI Tetrapyrrole Laboratory, Trinity Biomedical Sciences Institute, 152160 Pearse Street, Trinity College Dublin, The University of Dublin, Dublin 2, Ireland.

\section{Abstract}

A series of 5,15-disubstituted and 5,10,15,20-tetrasubstituted, and 5,10,15,20-tetrasubstituted$2,3,7,8,12,13,17,18$-octaethyl nickel(II) porphyrins in dichloromethane is reported to comprehensively access their sterically induced distortions from planarity. Thus, the tutorial review focuses on both resonance Raman spectroscopic investigations and structural investigations based on DFT. We relate different theoretical and experimental methodologies to predict out-of-plane distortions of the porphyrin macrocycles which are quantified by normal-coordinate structural decomposition. This comprehensive compilation reveals shortcomings in the molecular mechanic calculations and illustrates the impact of crystal packing forces on crystal structures. Non-planar distortions shift the experimentally observed resonance Raman marker bands $v_{2}, v_{3}$ and $v_{4}$ to lower frequency. A revised correlation between this shift and the calculated structural parameter (ruffling angle) is presented and reveals deviations from reported correlations based on molecular mechanics.

Key words: porphyrins, resonance Raman, conformational analysis, density functional theory, molecular mechanics, out-of-plane distortions. 


\section{Introduction}

Metalloporphyrins are a unique class of compounds with a wide variety of applications. They are utilized for light harvesting in, e.g., dye-sensitized solar cells [1] reaching efficiencies of up to $13 \%$ [2] and thus, exceeding the efficiency obtained with ruthenium-complex based devices while avoiding the cost incurred using the expensive metal ruthenium [3]. Besides their light harvesting properties metalloporphyrins also attract attention due to their electrocatalytic activity [4]. Hydrogen and oxygen evolution reactions catalyzed by nickel porphyrins have been reported $[5,6]$ as well as nickel porphyrin-based electrochemical sensors to detect nitric oxide release from a single cell $[7,8]$. Furthermore, the unique diagnostic and therapeutic potential of porphyrins, e.g., in tumor detection, tumor imaging and in the photodynamic treatment of malignancies are important motivations for porphyrin research [9-11]. Porphyrins are a ubiquitous class of compounds in nature. Classic examples are hemes, a group of iron porphyrins which serve as cofactor in proteins with multiple biological functions. Proteins such as myoglobin and hemoglobin are involved in reversible oxygen binding, while cytochromes function in reversible electron transfer processes. On the other hand, cytochromes P450 and peroxidases can perform oxidative transformations with a wide range of substrates [12]. The versatile biochemistry of cytochromes $P 450$ has triggered the industrial applications of P450s for the production of fine chemicals [13,14]. P450s allow for a variety of regioand enantioselective oxidation reactions, which are difficult to achieve by chemical synthesis $[13,14]$.

The wide-range use of porphyrins is related to the unique properties of the porphyrins macrocycle: The large delocalized $\pi$-system leads to pronounced absorption in the visible range [15] and stabilizes various oxidation states of the central metal ions [16]. Additionally, the structural flexibility of the porphyrin macrocycle is remarkable and significantly impacts the optical, chemical and electronic properties of porphyrins $[17,18]$. Coordination of metal ions, which are small compared to the cavity size of the planar porphyrin, induces out-of-plane (oop) distortions [17,19,20], for example, nickel(II) ions. The optimal metal-nitrogen distance for a planar metalloporphyrin is about $2.01 \AA$ [21,22], while $\mathrm{Ni}-\mathrm{N}$ bonds prefer a shorter bond length of $1.85 \AA$ [23]. As a result, the Ni-N bonds pull the pyrrole rings toward the center which induces oop deformations of the macrocycle. The actual degree of nonplanarity is determined by the energetic trade-off between the energy gain from shorter $\mathrm{Ni}-\mathrm{N}$ bonds within the contracted core of a non-planar porphyrin and the energy penalty arising from a decreased conjugation within the $\pi$-system of a non-planar porphyrin. The presence of substituents on the periphery of the macrocycle induces steric strain, which additionally contributes to non-planar distortions of nickel porphyrins. Thus, nickel porphyrins have been used to study the effect of nonplanar distortions on the properties of porphyrins and to mimic conformationally distorted porphyrins found in vivo $[18,24,25]$.

Distortion of the porphyrin macrocycle, in particular also the oop distortions of the macrocycle, have a significant impact on the chemical and photo-physical properties of nickel porphyrins [18], e.g., its affinity to axial ligation [26,27], redox potentials [28,29], optical absorption [30,31] and excited-state relaxation processes $[25,32,33]$. It can be demonstrated that the photo-physical properties of nickel porphyrins can be gradually altered by increasing the degree of non-planarity of the heterocycle, i.e. 
by gradually increasing the steric demand of peripheral substituents $[25,26,28]$. This highlights the possibility to fine-tune the photo-physical parameters of nickel porphyrins for a given application by controlling the degree and type of oop distortion.

In order to understand the impact of oop distortions on the physical and chemical properties of metalloporphyrins, the type and degree of oop distortions have to be defined: Shelnutt and coworkers $[34,35]$ introduced the concept of normal-coordinate structural decomposition (NSD), which represents a given macrocycle structure by displacements along the normal coordinates of a $D_{4 h}$-symmetric reference macrocycle (see Figure 1 and for details Chapter 2). In most cases [34], the observed nonplanarity can be adequately simulated by a linear combination of only the six lowest-frequency oop coordinates: saddling $\left(\mathrm{B}_{2 \mathrm{u}}\right)$, ruffling $\left(\mathrm{B}_{1 \mathrm{u}}\right)$, doming $\left(\mathrm{A}_{2 \mathrm{u}}\right)$, waving $(\mathrm{x})\left(\mathrm{E}_{g(\mathrm{x})}\right)$, waving $(\mathrm{x})\left(\mathrm{E}_{g(\mathrm{y})}\right)$ and propellering $\left(A_{1 u}\right)$ (minimal basis, see Figure $1 B$ ). For example, the structure of $[5,15-b i s(1-$ ethylpropyl)porphyrinato]nickel(II) (see Figure $1 \mathrm{~A}$ ) is essentially ruffled, i.e. strongly distorted along the lowest-frequency $\mathrm{B}_{1 \mathrm{u}}$ normal coordinate, while sad, dom and $\operatorname{wav}(y)$ distortions contribute only sparsely. Expressing the macrocycle distortion in terms of normal coordinates simplifies the description of non-planarity and provides an alternative to comparing frequently used structural parameters, e.g., Ni-N distance and ruffling dihedral angle $\mathrm{C}_{a}-\mathrm{N}-\mathrm{N}-\mathrm{C}_{a}$ (see Figure $1 \mathrm{~A}$ ). The simulation of a given, i.e. observed macrocycle distortion, can be improved by extending the minimal basis, i.e. by including both the lowest- and the second-lowest-frequency normal coordinate of all symmetries. Even if small, such higher order deformations contribute to the observed physical and chemical properties, as, e.g., to the red-shift of the Soret-band in non-planar nickel porphyrins [31].

While the biologically relevant hemes are planar without the apoprotein macrocycle, distortions are prevalent in heme proteins (i.e., the functional holoprotein) and induced by the protein scaffold in the vicinity of the binding pocket [35-37]. Usually, the interaction with the asymmetric protein environment leads to simultaneous and significant displacements along several lowest-frequency normal coordinates. Noteworthy, similar macrocycle distortions are found for specific functional class of heme proteins from different species, suggesting that the observed macrocycle distortion is functionally relevant $[34,35]$. For example, the distortion of heme in mitochondrial cytochrome $\mathrm{c}$ (from rice, horse and tuna) is dominated by the ruf distortion type with displacements of 0.7 to $1.0 \AA$ [34]. On the other hand, the iron porphyrin cofactors in peroxidases are characterized by strong sad distortions of -0.6 to $-0.9 \AA$ and ruf distortions of -0.3 to $-0.7 \AA$ [34]. Likewise, the reversible oxygen binding proteins hemoglobin and myoglobin exhibit significant contributions of doming ( $0.3 \AA$ in myoglobin, 0.4 to $0.5 \AA$ for in hemoglobin) $[34,35]$. The total oop distortion of these oxygen binding cofactors $(0.4 \AA$ in myoglobin, $0.6 \AA$ in hemoglobin) is similar to that in cytochromes P450 (0.4 to $0.5 \AA$ ), but small compared to other heme proteins such as peroxidases $(0.7$ to $1.2 \AA)$ and mitochondrial cytochromes $c$ (0.8 to $1.1 \AA$ ) [34]. Several investigation suggest that the protein-induced distortion of the heme prosthetic group is a critical factor for its biological function [18,20,35,38]. An established role of heme ruffling is the tuning of the reduction potential and electronic coupling in cytochrome $\mathrm{c}$, which alters the electron transfer efficiency [39-42]. The distortion of the porphyrin macrocycle also impacts the affinity to axial ligand such as oxygen [27,43-45]. Non-planar distortions also affect the chlorophylls in 
photosynthesis [38,46]. Nickel is found as the central metal in cofactor F430 in methyl-coenzyme M reductase and the importance of the nickel ion in regulating the macrocycle conformation has been clearly established [20,47-51].

In order to understand the impact of macrocycle distortions on the chemical and photo-physical properties of metalloporphyrins in solution and in vivo, nickel(II) porphyrins are an important and useful model system [20,52,53]. However, the NSD analysis of nickel(II) porphyrins and the resulting structural parameters are often based on crystallographic structures. Although several studies suggest a good agreement between the structure in the solid state and the actual structure in solution - and thus in vivo - [54,55], the molecular structure in the solid state may be altered as a result of packing forces in the crystal and $\pi-\pi$-interactions between neighboring porphyrins [26,56-59]. The impact of packing forces can be inferred from a comparison of the non-planar distortions for structurally similar porphyrins [26], multiple crystallographically independent molecules in the unit cell [60], and/or in crystal isomorphs [61]. For example, (5,10,15,20-tetrapentylporphyrinato)nickel(II) is strongly ruffled in the solid state, while the macrocycle with propyl instead of pentyl substituents is almost planar with only small contributions of a waving deformation [26]. Although small, these waving deformations correspond to a considerable deformation energy and arise from crystal packing forces [26]. Resonance Raman [26] and XAFS studies [57] confirm that the structure of the tetrapropyl substituted porphyrin is not planar in solution. The effects of crystal packing forces are also discussed for $[2,3,7,8,12,13,17,18$-octaethylporphyrinato]nickel(II) (NiOEP), which is observed in both planar and non-planar crystalline forms [61].

To study the porphyrin structure without distortions arising from crystal packing forces, spectroscopic probes are needed to characterize the oop distortions of porphyrins in various environments, i.e. ideally ranging from crystals to biological in vivo settings. In this regard, resonance Raman spectroscopy [62] has been particularly useful. Several structure-sensitive resonance Raman bands in the high-frequency region between 1200 and $1700 \mathrm{~cm}^{-1}$ shift to a lower frequency with increasing nonplanarity of the macrocycle. This frequency shift was investigated for a series of several nickel porphyrins with a gradual increasing steric demand of the substituents [24,26,31,63-67] and correlated to structural parameters, e.g., the Ni-N distance and the ruffling dihedral angle $\mathrm{C}_{\mathrm{a}}-\mathrm{N}-\mathrm{N}-\mathrm{C}_{\mathrm{a}}$. Both ruffling and saddling - which are frequently observed for metalloporphyrins - shift the structuresensitive ip modes to lower frequencies $[24,64,68]$. As a consequence, the ruf and sad distorted conformers cannot be distinguished from the high-frequency region of the resonance Raman spectrum. However, indicators for the type of macrocycle deformation are oop modes in the lowfrequency region of the resonance Raman spectrum, i.e. below $800 \mathrm{~cm}^{-1}$. These modes become (resonance) Raman active if the oop mode and the distortion of the macrocycle have the same symmetry $[69,70]$. The coexistence of planar and non-planar conformations of NiOEP [71] and $(5,10,15,20$-tetraphenylporphyrinato)nickel(II) [72] in solution was proven by temperature-dependent resonance Raman measurements. Furthermore, resonance Raman spectroscopy was successfully applied to probe porphyrin-protein interactions and to monitor the ligation status of heme in heme proteins [73-76]. The resonance Raman spectra of porphyrins are also highly sensitive to chemical 
alteration of the macrocycle. In this regard, we applied resonance Raman spectroscopy to probe the reactivity of singly-reduced nickel(II) porphyrins towards the formation of nickel(II) phlorin anions [77], which are discussed as a key intermediate in electrocatalytic hydrogen evolution reactions [5].

To corroborate such spectroscopic methods for the examination of macrocycle non-planarity, theoretical chemistry has become increasingly valuable. Molecular mechanics (MM) calculations [78] based on an empirical determined porphyrin force field [64,79] - enable the prediction of different conformers, their energies $[26,64,66,67]$ and vibrational frequencies [80]. Particular shortcomings of the MM approach using empirical force fields can be overcome with quantum mechanics. Contrary to calculations with the empirical force field, density functional theory (DFT) calculations predict a (slightly) non-planar structure for (porphyrinato)nickel(II), which was indeed spectroscopically proven $[58,66,81,82]$. The normal modes of nickel porphyrins are better reproduced by DFT than by the empirical force field $[58,83]$. DFT calculations and their time-dependent counterparts allow for the simulation of resonance Raman spectra for a particular molecular equilibrium geometry $[70,84]$. These calculations can verify the calculated molecular geometry by comparing the simulated spectra with experimental ones [74]. With molecular dynamics [78,83], structural fluctuations within an ensemble of energetically close conformational states can be simulated yielding a time-averaged structure, rather than a particular minimum energy geometry $[31,85]$. Systematic resonance Raman studies of various nickel porphyrin with gradually increasing non-planarity (vide supra) - published in the 1990's and 2000 's - had to rely on crystal structures and molecular calculation based on the then state-of-the-art MM with empirical force fields $[24,26,63-67,69]$. However, today ground-state geometry optimizations by DFT are feasible and might give additional insights.

This review gives an overview of the sterically induced distortions and resonance Raman spectroscopic features of metalloporphyrins using a series of nickel(II) porphyrins, i.e., 5,15disubstituted and 5,10,15,20-tetrasubstituted, and 5,10,15,20-tetrasubstituted-2,3,7,8,12,13,17,18octaethyl nickel(II) porphyrins (see Figure 2 for structures). The first part of the review describes the NSD method used to analyze the macrocycle distortions of the nickel(II) porphyrins. Subsequently, Xray crystal structures of nickel(II) porphyrins are compared to reported structures calculated by MM. To provide a statistically significant basis for investigations and to identify general trends, the structures of 18 nickel(II) porphyrins were obtained here by DFT calculations. This second part of the review points out the effects of crystal packing forces on the structure of nickel(II) porphyrins as well as shortcomings in the MM calculations compared to DFT calculations. Finally, the third part gives an overview of resonance Raman spectroscopy as an experimentally technique to determine the degree of macrocycle ruffling in solution. The correlations between structure-sensitive Raman frequencies and the porphyrin macrocycle distortion are summarized, which includes an updated correlation based on the DFT calculations performed here. The review includes six previously unreported nickel(II) porphyrins. To link literature data with the current state-of-the-art in the field, resonance Raman spectra of 18 nickel(II) porphyrins are discussed, including 11 previously unreported ones. 


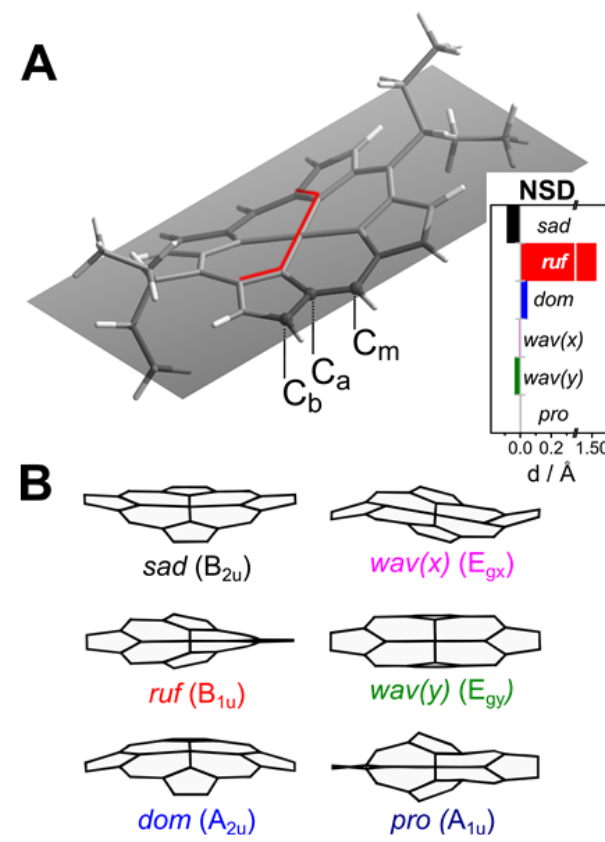

Figure 1: Structure of NiD(1-Et-Pr)P - calculated at the DFT level of theory - reveals the out-of-plane distortion of the porphyrin macrocycle (A). Displacements $d$ (in $\AA$ ) along the lowest-frequency out-ofplane normal coordinates are determined by normal-coordinate structural decomposition (NSD, results in bar chart). The effect of a $1 \AA$ deformation is illustrated for each of these normal-coordinates (B, adopted from reference [66]). Figure $A$ highlights one of the ruffling dihedral angles cis- $\mathrm{C}_{a}-\mathrm{N}-\mathrm{N}-\mathrm{C}_{\mathrm{a}}$ (red line), the mean-square plane - determined by the 24 macrocycle atoms - (grey plane) and the position of meso $\left(C_{m}\right), \alpha\left(C_{a}\right)$ and $\beta\left(C_{b}\right)$ carbon atoms.

NiD(alkyl)P and NiD(aryl)P

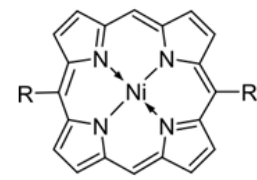

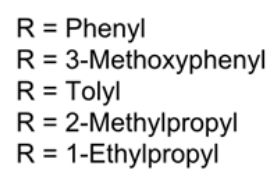

NiT(alkyl)P and NiT(aryl)P

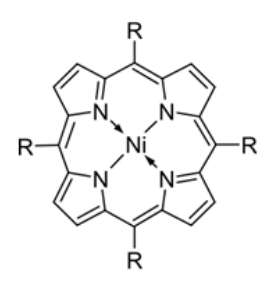

$$
\begin{array}{ll}
\mathrm{R}=\text { Phenyl } & \mathrm{NiT}(\mathrm{Ph}) \mathrm{P} \\
\mathrm{R}=\text { 4-Methoxyphenyl } & \mathrm{NiT}(4-\mathrm{MeOPh}) \mathrm{P} \\
\mathrm{R}=n \text {-Butyl } & \mathrm{NiT}(\mathrm{Bu}) \mathrm{P} \\
\mathrm{R}=n \text {-Hexyl } & \mathrm{NiT}(\mathrm{He}) \mathrm{P} \\
\mathrm{R}=\text { 2-Methylpropyl } & \text { NiT(2-Me-Pr)P } \\
\mathrm{R}=\text { lsopropyl } & \text { NiT(iPr)P } \\
\mathrm{R}=\text { 1-Methylpropyl } & \text { NiT(1-Me-Pr)P } \\
\mathrm{R}=\text { 1-Ethylpropyl } & \text { NiT(1-Et-Pr)P } \\
\mathrm{R}=\text { tert-Butyl } & \mathrm{NiT}(\mathrm{tBu}) \mathrm{P}
\end{array}
$$

NiOET(aryl)P

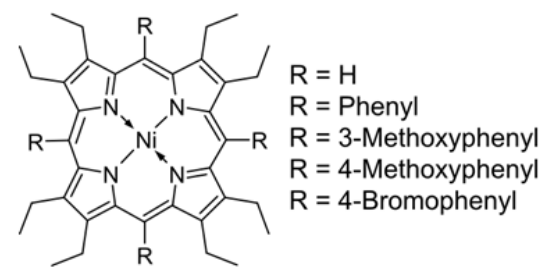

NiOEP

NiOET(Ph)P

NiOET(3-MeOPh)P

NiOET(4-MeOPh)P

NiOET(4-Br-Ph)P

Figure 2: Structures and acronyms of the nickel porphyrins investigated. 


\section{Normal-Coordinate Structural Decomposition (NSD)}

NSD is a structural decomposition method for classifying and quantifying the oop and ip distortions of a porphyrin macrocycle [35]. As reference structure for the NSD procedure serves a planar $D_{4 \mathrm{~h}^{-}}$ symmetric copper porphyrin [(porphyrinato)copper(II), copper "porphine"]. The energy-minimized structure and normal modes of this reference structure were determined by MM calculations $[35,64,67]$. The displacements along the normal modes obtained are denoted as normal deformations $\widehat{\mathrm{D}}_{\mathrm{k}}$. These normal deformations are normalized displacements, which is, the square root of the sum of the squares of the displacements of the 24 macrocycle atoms is $1 \AA$. The $D_{4 h}$-symmetric porphyrin macrocycle with its 24 atoms has 66 normal modes ( $3 \mathrm{~N}-6)$, i.e., 66 normal deformations $\widehat{\mathrm{D}}_{\mathrm{m}}$, consisting of 21 oop and 45 ip (in-plane) normal deformations. Any distorted macrocycle can exactly be represented by this full basis set.

It was shown, that the crystal structures of many synthetic and protein-bound metalloporphyrins can be adequately simulated by a linear combination of only the lowest-frequency ip and oop normal deformations (minimal basis) [35]. The lowest-frequency oop normal deformations are displayed in Figure $1 \mathrm{~B}$ and are donated as: saddling $\left(\mathrm{B}_{2 \mathrm{u}}\right)$, ruffling $\left(\mathrm{B}_{1 \mathrm{u}}\right)$, doming $\left(\mathrm{A}_{2 \mathrm{u}}\right)$, waving $(\mathrm{x})\left(\mathrm{E}_{g(\mathrm{x})}\right)$, waving $(\mathrm{x})$ $\left(E_{g(y)}\right)$ and propellering $\left(A_{1 u}\right)$ (see Figure $1 B$ ). The symmetry of these normal deformations is classified according to the $D_{4 \mathrm{~h}}$ point group and given in brackets.

The following procedure describes the decomposition of the oop distortion into the lowest frequency normal deformations. The oop distortion of a macrocycle is represented by a linear combination of the lowest-frequency normal deformations $\widehat{\mathrm{D}}_{\mathrm{k}}$,

$$
\Delta \mathbf{z}_{\text {sim }}=d_{\text {sad }} \widehat{\mathbf{D}}_{\text {sad }}+d_{\text {ruf }} \widehat{\mathbf{D}}_{\text {ruf }}+d_{\text {dom }} \widehat{\mathbf{D}}_{\text {dom }}+d_{\text {wav }(\mathrm{x})} \widehat{\mathbf{D}}_{\text {wav }(\mathrm{x})}+d_{\text {wav }(\mathrm{y})} \widehat{\mathbf{D}}_{\text {wav }(\mathrm{y})}+d_{\text {pro }} \widehat{\mathbf{D}}_{\text {pro }}=\sum_{\mathrm{k}=1}^{6} d_{\mathrm{k}} \widehat{\mathbf{D}}_{\mathrm{k}}
$$

where $\Delta \mathbf{z}_{\text {sim }}$ is a 24-dimensional vector representing the displacement of each atom with respect to the least-squares mean plane of the 24 macrocycle atoms. The coefficient $d_{\mathrm{k}}$ gives the displacements (in $\AA$ ) along the normal deformation $\widehat{D}_{\mathrm{k}}$ and is obtained by solving the least square problem,

$$
\begin{gathered}
f\left(d_{\mathrm{k}}\right)=\left|\Delta \mathbf{z}_{\mathrm{sim}}-\Delta \mathbf{z}_{\mathrm{obs}}\right|^{2}=\left|\sum_{\mathrm{k}=1}^{6} d_{\mathrm{k}} \widehat{\mathrm{D}}_{\mathrm{k}}-\Delta \mathbf{z}_{\mathrm{obs}}\right|^{2}=\text { minimum } \\
\frac{\partial f\left(d_{\mathrm{k}}\right)}{\partial d_{\mathrm{k}}}=0
\end{gathered}
$$

which requires that the square of $\left|\Delta \mathbf{z}_{\text {sim }}-\Delta \mathbf{z}_{\mathrm{obs}}\right|$, i.e. the difference between the simulated oop deformation $\Delta \mathbf{z}_{\text {sim }}$ and the observed oop deformation $\Delta \mathbf{z}_{\mathrm{obs}}$, becomes minimal. For the decomposition of the ip distortion, the ip displacements, $\Delta x$ and $\Delta y$, are given with respect to the mentioned copper porphyrin reference structure. The NSD analysis using all oop and ip normal deformations is described in detail by Jentzen et al. [35].

The results of the NSD analysis can be summarized in a graph as, for example, depicted in the inset of Figure 1A. This graph shows that the macrocycle of [5,15-bis(1-ethylpropyl)porphyrinato]nickel(II) is with $d_{\text {ruf }}=1.58 \AA$ strongly displaced along the ruf mode, while sad, $\operatorname{dom}, \operatorname{wav}(x), \operatorname{wav}(y)$ and pro 
displacements are smaller than $d<0.1 \AA$ and thus contribute only sparsely to the observed macrocycle distortion.

Due to the fact, that the lowest-frequency oop normal deformations only span a 6-dimensional and not the full 21-dimensional coordinate space, the simulated macrocycle deformation $\left(\Delta \mathbf{z}_{\text {sim }}\right)$ does not exactly represent the observed one $\left(\Delta \mathbf{z}_{\text {obs }}\right)$. To evaluate the goodness of fit, the mean deviation $\bar{\delta}_{\text {oop }}$ between the simulated and the observed out-of-plane displacements is considered [35], which is given by

$$
\bar{\delta}_{\text {oop }}=\frac{1}{24} \sum_{\mathrm{n}=1}^{24}\left|\left(\Delta \mathbf{z}_{\text {sim }}\right)_{\mathrm{n}}-\left(\Delta \mathbf{z}_{\text {obs }}\right)_{\mathrm{n}}\right|
$$

For reference, in x-ray crystallography, the mean positional error for a single atom is about $0.006 \AA$ in three dimensions (and $0.003 \AA$ in one dimension) (assuming a refinement factor, R-value, of 0.07 ) [34].

The vibrational frequency for the copper porphyrin reference macrocycle, obtained from the normal mode calculations by MM calculations, are 65 (sad), 88 (ruf), 135 (dom), 65 ( $\mathrm{sad}), 176$ (wav $(x)$, $\operatorname{wav}(y))$ and $335 \mathrm{~cm}^{-1}$ (pro) [35]. Thus, a porphyrin macrocycle is easier to distort along, e.g., the sad and the ruf mode than along the pro mode. As will be shown in the next chapter, the actual distortion of the macrocycle depends on the peripheral substituents and the substitution pattern of the macrocycle. Due to the small amount of energy necessary to deform the porphyrin macrocycle, packing forces can affect the macrocycle distortion and thus lead to a difference between the structure in the solid state ( $\mathrm{x}$-ray crystallography) and the structure in solution.

The NSD analysis can be performed using a program available online [86].

\section{Classification of Nickel(II) Porphyrins Structures}

To illustrate the sterically induced distortions of the nickel(II) porphyrins investigated (Figure 2), structures from X-ray crystallography, MM calculations [78] and DFT calculations are considered. For this comparison, the structures are analyzed by NSD and the displacements along the lowestfrequency oop normal modes are summarized in Figure 3-6. All nickel(II) porphyrins exhibit strong oop distortions with displacements of at least $0.9 \AA$ along the ruf or $4.0 \AA$ along the sad mode. First, the structures of nickel(II) porphyrins derived from our DFT calculations will be briefly described, while a comprehensive analysis and comparison with MM and crystal structures follows subsequently. The series of nickel(II) porphyrins is divided into three groups: (i) NiD(alkyl)P and NiT(alkyl)P porphyrins, (ii) NiD(aryl)P and NiT(aryl)P porphyrins, and (iii) NiOET(aryl)P porphyrins (see Figure 2).

The calculated structures of the di- and tetraalkyl substituted porphyrins are essentially ruffled (see Figure 3 and 4). Increased steric strain induced by spatially more demanding substituents or by a higher number of meso-substituents is relieved by an increased ruf distortion. However, NiT(2-MePr)P exhibits significant contributions of saddling $(0.26 \AA)$ and waving(y) $(0.13 \AA)$ in addition to the ruf 
distortion $(2.20 \AA)$. Distortions along these higher frequency normal modes of the minimal basis are associated with (asymmetric) alkyl chains bearing two $y$-carbon atoms.

In contrast to the essentially ruffled alkyl-substituted porphyrins, the macrocycle of the di- and tetraaryl-substituted porphyrins is distorted by a mixture of ruffling and saddling (see Figure 5). Saddling sterically enables the rotation of the aryl-substituents into the porphyrin plane and thus increases the energetically favorable overlap for the $\pi$-system of the peripheral aryl-substituents and the macrocycle [87]. A larger number of meso-substituents increases the driving force associated with saddling, thus causing a strong increase of saddling upon increasing the number of meso-arylsubstituents from two (NiD(aryl)P) to four (NiT(aryl)P).

NiOET(aryl)P porphyrins are essentially saddled (see Figure 6). The sterically crowded NiOET(aryl)P shows large saddle distortions and almost no contribution from ruffling. Apparently, the steric repulsion between neighboring peripheral substituents is most effectively minimized by distortion along the saddling mode.

The DFT calculations assign different types and degrees of oop deformations to specific porphyrins compared to the results of MM calculations (Figure 3-6). In particular: (i) Based on MM, a gabled distortion was previously assumed for NiD(alkyl)P porphyrins, i.e. a contribution of both ruf and dom distortion [65,67], while DFT predicts an essentially ruf conformation (see Figure 3). (ii) Compared to DFT, MM slightly overestimates the ruf distortion of NiT(alkyl)P porphyrins with primary alkyl substituents, while for the corresponding porphyrins with tertiary alkyl substituents an overestimation was found (see Figure 4) [26]. (iii) A mixture of ruf and sad distortion is predicted for NiD(aryl)P and $\mathrm{NiT}(\operatorname{aryl}) \mathbf{P}$ porphyrins by DFT, which is experimentally supported [88]. In contrast, MM gives purely ruf distorted conformers for these porphyrins (see Figure 5) [26,67,72]. A comparison of the nickel(II) porphyrin structures calculated by DFT and MM to their reported crystal structures (Figure 3-6) leads to the conclusion, that in some cases crystal packing forces strongly impacts the porphyrin macrocycle distortion.

\section{Normal-Coordinate Structural Decomposition}

The calculated structures are analyzed using only the minimal basis, i.e. the lowest-frequency oop and ip normal modes. To quantify the goodness of fit the mean deviation $\bar{\delta}_{\text {oop }}$ between the simulated and observed oop displacement of the 24 macrocycle atoms is considered [35]. This value is $0.01 \AA$ or less for the investigated series of NiD(alkyl)P and NiT(alkyl)P porphyrins. In the case of the strongly distorted NiT(tBu)P the mean deviation for the oop distortions is $0.03 \AA$, i.e. larger compared to porphyrins with less sterically demanding alkyl-substituents. The aryl-substituted porphyrins exhibit slightly higher mean deviation in comparison to their alkyl-substituted counterparts. For the series of NiD(aryl)P, NiT(aryl)P and NiOET(aryl)P the mean deviations are $0.01,0.02$ and $0.04 \AA$, respectively. For each of the porphyrins investigated the mean deviation for the oop distortions is small compared to the total oop distortion of $0.95-4.05 \AA$. Thus, the minimal basis is considered as appropriate to simulate the observed structures and to compare the oop distortion of the investigated 
porphyrins. The agreement between observed and simulated structure can be improved by decomposing the observed structure with an extended basis, which includes both the lowest and the second lowest-frequency normal coordinates of each symmetry type. The complete results of the NSD including the mean deviations and total distortion for the oop and ip displacements using the minimal basis are tabulated in the Supporting Information (see Table S1-3 and Figure S8).

\section{NiD(alkyl)P and NiT(alkyl)P Porphyrins}

The series of NiD(alkyl)P and NiT(alkyl)P porphyrins are essentially ruffled (see Figure 3 - 4). The distortion along normal modes other than ruf reaches maximal values of $0.14 \AA$, which is small compared to observed ruf displacements of 1.10 to $2.91 \AA$. This is not the case for NiT(2-Me-Pr)P, which exhibits contributions of saddling $(0.26 \AA)$ and waving $(y)(0.13 \AA)$ besides the ruf distortion $(2.20$ A).

For the series of NiD(alkyl)P and NiT(alkyl)P porphyrins the simulated ruf displacement ( $\mathrm{d}_{\text {ruf }}$ ) as well as the observed total oop displacement increases in the following order: NiD(2-Me-Pr)P $(1.10 \AA)<<$ NiD(1-Et-Pr)P $(1.59 \AA)$ < NiT(2-Me-Pr)P $(1.62 \AA)<$ NiT(Bu)P $(1.92 \AA)$, NiT(He)P $(1.93 \AA)<<$ NiT(1Et-Pr)P $(2.12 \AA)<\operatorname{NiT}(\mathrm{iPr}) \mathbf{P}(2.19 \AA)<\mathrm{NiT}(1-\mathrm{Me}-\mathrm{Pr}) \mathrm{P}(2.20 \AA)<<\mathrm{NiT}(\mathrm{tBu}) \mathbf{P}(2.90 \AA)$. The sequence observed illustrates the following: (i) Increasing the number of meso-substituents significantly increases the degree of ruffling. The tetrasubstituted NiT(2-Me-Pr)P and NiT(1-Et-Pr)P are stronger displaced along ruf than the corresponding disubstituted porphyrins, NiD(2-Me-Pr)P and NiD(1-EtPr)P). (ii) The degree of ruffling increases with the steric demand of the meso-alkyl-substituents, which is the highest for substituents with tertiary $\alpha$-carbon atoms, considerably lower for secondary and lowest for primary a-carbon atoms. The ruf displacement for the NiT(alkyl)P porphyrins, which amounts to $1.62-1.74 \AA$ for primary substituents, $2.12-2.20 \AA$ for secondary substituents and $2.90 \AA$ for tertiary substituents, clearly illustrates this trend. Despite its larger secondary alkyl-substituent, both the ruf displacement $\left(\mathrm{d}_{\text {ruf }}\right)$ and the observed total oop displacement $\left(D_{\text {oop }}\right)$ is smaller for NiT(1-Et-Pr)P $\left(\mathrm{d}_{\text {ruf }}=2.12 \AA, D_{\text {oop }}=2.12 \AA\right)$ than for NiT(iPr)P $\left(d_{\text {ruf }}=2.19 \AA, D_{\text {oop }} 2.20 \AA\right)$. Rather than an increase in ruf displacement, the larger 1-ethylpropyl substituent of NiT(1-Et-Pr)P with the presence of its two $Y$ carbon atoms induces additional displacements along higher frequency normal modes of the minimal basis: $\operatorname{dom}(0.04 \AA), \operatorname{wav}(x)(0.02 \AA)$ and $\operatorname{wav}(y)(0.04 \AA)$. For NiT(iPr)P these oop displacements are essentially nonexistent, i.e. smaller than $0.01 \AA$.

As mentioned above, small contributions of distortions other than ruf are observed for the NiD(alkyl)P and NiT(alkyl)P porphyrins. The degree and type of these additional distortions strongly depend on the type of substituents: A small contribution of saddling is observed for all alkyl-substituted porphyrins $(0.01-0.14 \AA)$, except for the porphyrins with $n$-alkyl chains, which exhibit a small dom distortion $(0.04 \AA)$, i.e. a deformation along the third highest frequency normal coordinate of the minimal basis. Waving, i.e. a deformation along one of the two second highest frequency normal modes, is only observed for the porphyrins with two y-carbon atoms, e.g., NiD(2-Me-Pr)P $\left(d_{d o m}=0.02 \AA, d_{\text {wav }(x)}=0.05\right.$ $\left.\AA, d_{\text {wav }(y)}=0.03 \AA\right), \operatorname{NiD}(1-E t-P r) P\left(d_{\text {dom }}=0.05 \AA, d_{\text {wav }(x)}=0.01 \AA, d_{\text {wav }(y)}=0.04 \AA\right), \operatorname{NiT}(2-M e-P r) P$ $\left(d_{\text {dom }}=0.00 \AA, d_{\text {wav }(x)}=0.02 \AA, d_{\text {wav }(y)}=0.13 \AA\right), \operatorname{NiT}(1-E t-P r) P\left(d_{\text {dom }}=0.04 \AA, d_{\text {wav }(x)}=0.02 \AA, d_{\text {wav }(y)}=\right.$ 
$0.04 \AA$ ). Propelling distortions, i.e. displacements along the highest frequency normal coordinate of the minimal bases, are not observed.

The macrocycle of the investigated dialkyl- and tetraalkyl-meso-substituted nickel porphyrins is essentially ruffled, although distortion along the ruf normal mode is energetically slightly more demanding (88 $\mathrm{cm}^{-1}$, calculated based on an atomic force field approach) [35] than along the softer sad normal mode $\left(65 \mathrm{~cm}^{-1}\right)$. Small metal ions such as nickel(II) favor ruffling over saddling as ruffling contracts the porphyrin core more than saddling and thus provides a shortened and more favorable $\mathrm{Ni}-\mathrm{N}$ bond distance [65]. Additionally, the distortion along the ruffling normal mode effectively decreases the steric repulsion between the peripheral substituents and the porphyrin macrocycle. The ruf distortion places the meso-carbon atoms alternatingly above and below the macrocycle mean plane. This motion tilts the peripheral substituents away from the porphyrin macrocycle and thus reduces the steric repulsion between these substituents and the porphyrin macrocycle - in particular to the closest $\beta$-carbon atoms of the porphyrin macrocycle (see Figure $1 \mathrm{~A}$ for illustration of the NiD(1Et-Pr)P structure). Thus, ruffling is observed for the dialkyl- and tetraalkyl-meso-substituted nickel porphyrins. As noted for NiD(alkyl)P and NiT(alkyl)P porphyrins, increased steric strain induced by spatially-demanding substituents or by a higher number of meso-substituents is relieved by increasing the ruf distortion.

According to MM, NiD(alkyl)P porphyrins exhibit a mixture of ruf and dom distortion (see Figure 3) [67]. In contrast, DFT calculations predict an essentially ruffled macrocycle with minor contributions of $\operatorname{sad}, \operatorname{dom}, \operatorname{wav}(x)$ and $\operatorname{wav}(y)$. This is apparent by comparing the MM structure for NiD(iPr)P [65] ( $\mathrm{d}_{\mathrm{ruf}}=$ $\left.1.47 \AA, d_{\text {dom }}=0.23 \AA\right)$ and NiD(tBu)P [67] $\left(d_{\text {ruf }}=2.01 \AA, d_{\text {dom }}=0.54 \AA\right)$ with the DFT structure of the structurally similar NiD(1-Et-Pr)P $\left(d_{\text {ruf }}=1.59 \AA, d_{\text {dom }}=0.05 \AA\right)$. The results of the MM calculations are supported by the crystal structures of $\mathbf{N i D}(\mathrm{iPr}) \mathbf{P}$ and $\mathbf{N i D}(\mathrm{tBu}) \mathbf{P}$, which exhibit similar degrees of ruf and dom distortions (see Figure 3). However, nickel porphyrins are prone to deformation in the solid state due to packing forces and non-planar deformation of the porphyrin ring. It should be noted that the empirical force field used for the MM calculations is derived from and refined for nickel porphyrin crystal structures (vide supra) [67]. Thus, the predicted mixture of ruf and dom distortions for NiD(alkyl)P might originate from a shortcoming of MM calculations. For the series of NiD(alkyl)P porphyrins investigated only the crystal structure of NiD(2-Me-Pr)P has been reported [89]. However, this compound forms $\pi$ - $\pi$-dimers, which leads to an almost planar macrocycle. Thus, this situation cannot be considered for a comparison to the DFT structure.

For NiT(alkyl)P porphyrins DFT calculations predicts an essentially ruf distortion of the macrocycle which is in line with MM calculations [26] (see Figure 4). However, compared to DFT, MM slightly underestimates the degree of ruffling upon increasing the sterically demand of the substituents: NiT(Bu)P (DFT: $1.92 \AA$ ), NiT(Pr)P (MM: $1.80 \AA$ ), NiT(iPr)P (DFT: $2.19 \AA$, MM: $2.23 \AA$ ), NiT(tBu)P (DFT: $2.90 \AA$, MM: $2.74 \AA$ ) [26]. According to DFT and MM calculations, the crystal structures for NiT(alkyl)P porphyrins exhibit strong contributions of ruf distortion (see Figure 4). Additional sad distortions are observed in the crystal structure of $\operatorname{NiT}(\mathbf{P e}) \mathbf{P}[26]\left(\mathrm{d}_{\mathrm{sad}}=0.46 \AA, \mathrm{d}_{\mathrm{ruf}}=1.57 \AA\right)$ and 
NiT(iPr)P [90] ( $\left.d_{\text {sad }}=0.46 \AA, d_{\text {ruf }}=2.03 \AA\right)$. Although sad distortions are observed for NiT(iPr)P, it is not observed in the crystal structure of structurally similar NiT(1-Et-Pr)P [91] ( $d_{\text {sad }}=0.00 \AA, d_{\text {ruf }}=2.25$ A). DFT and MM calculations predict much smaller sad distortions for NiT(Pe)P and NiT(iPr)P with displacements of less than $0.10 \AA$. Thus, the strong sad distortion observed in crystals of these porphyrins might originate from crystal packing forces. The impact of crystal packing forces on the conformation of the macrocycle is also apparent for NiT(Pr)P which is almost planar in the solid state [26], while the crystal structure of the structurally similar $\mathbf{N i T}(\mathrm{Pe}) \mathbf{P}$ and the DFT structure of $\mathbf{N i T}(\mathrm{Bu}) \mathbf{P}$ show strong non-planar distortions. The calculated $\mathrm{Ni}-\mathrm{N}$ distance for $\mathrm{NiT}(\mathrm{Bu}) \mathbf{P}$ is $1.93 \AA$ according to DFT calculations, which is consistent with the 1.90(2) $\AA \mathrm{Ni}-\mathrm{N}$ distance for NiT(Pr)P in solution determined by extended $X$-ray absorption fine structure spectroscopy [57]. DFT calculations predicted small wav distortions, i.e. displacements along a higher frequency normal coordinate of the minimal basis. However, such wav displacements are only found for porphyrins with substituents bearing two Y-carbon atoms, e.g., for NiT(2-Me-Pr)P and NiT(1-Et-Pr)P. The crystal structures of NiT(2-Me-Pr)P [91] and NiT(1-Et-Pr)P [91] exhibit small contributions of wav, too. However, in the crystal almost all NiT(alkyl)P porphyrins exhibit wav deformation (see Figure 4), which is likely to arise from crystal packing forces in many cases. Thus, the crystal structures are not reliable to address the question if wav deformations occur for porphyrins with substituents bearing two $\mathrm{Y}$-carbon atoms.

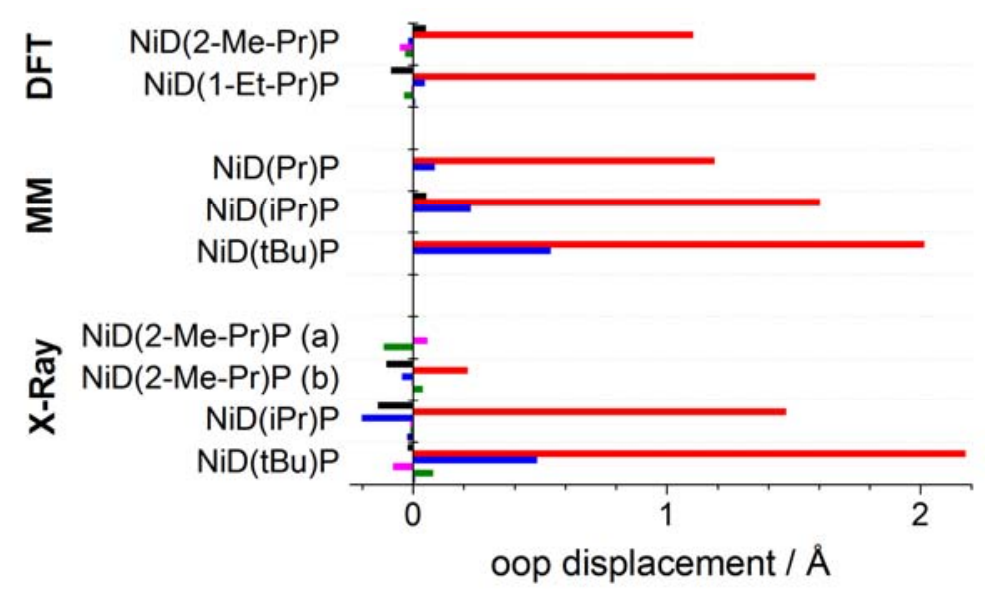

Figure 3: Displacements along the lowest-frequency oop normal coordinates for NiD(alkyl)P porphyrins: sad (black), ruf (red), dom (blue), wav(x) (magenta), wav(y) (olive) and pro (navy). Structures are calculated with DFT (this study) and compared to reported MM calculations (values taken from literature) [67] and to crystal structures (X-ray): NiD(2-Me-Pr)P (two conformers in unit cell) [89], NiD(iPr)P [65], NiD(tBu)P [67]. 


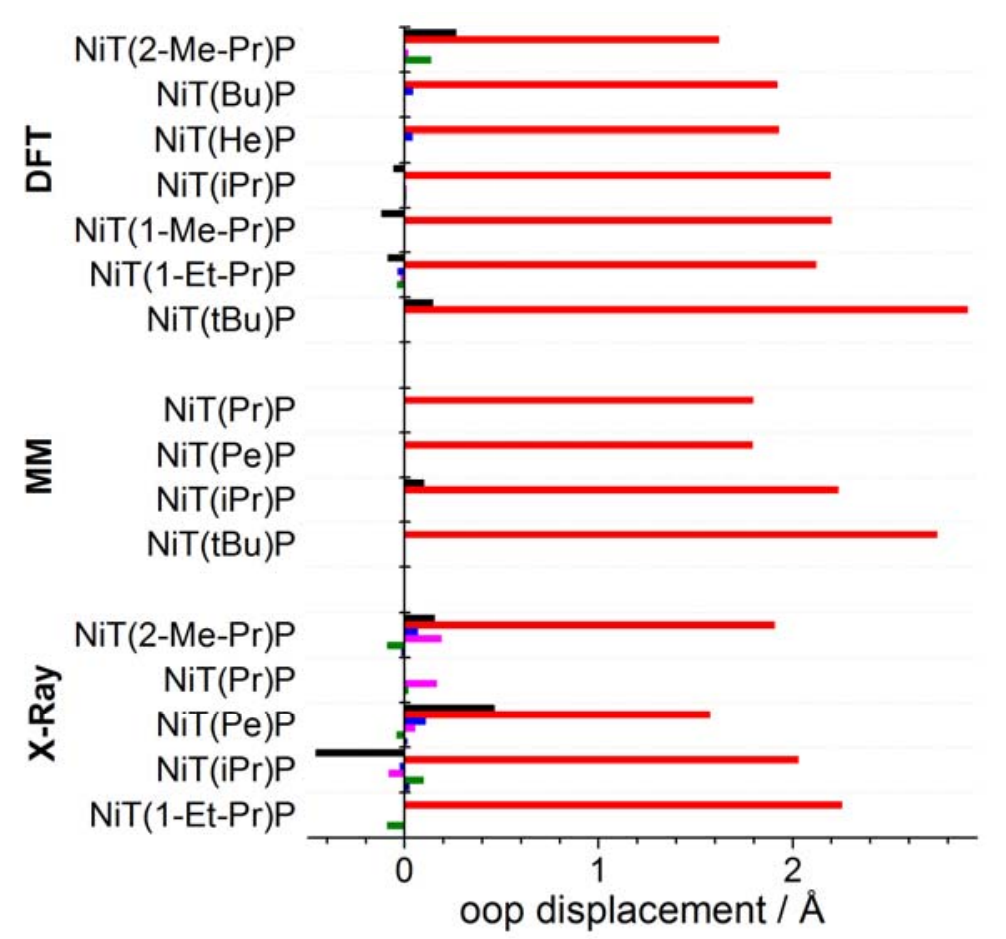

Figure 4: Displacements along the lowest-frequency oop normal coordinates for NiT(alkyl)P porphyrins: sad (black), ruf (red), dom (blue), wav(x) (magenta), wav(y) (olive) and pro (navy). Structures are calculated with DFT (this study) and compared to reported MM calculations (values taken from literature, [26]) and to crystal structures (X-Ray): NiT(2-Me-Pr)P [91], NiT(iPr)P [90], NiT(1Et-Pr)P [91] and NiT(Pe)P (four independent porphyrins per unit cell with similar oop distortions, parameters for porphyrin containing nickel atom number 4, [26]). oop displacements in the crystal structure of NiT(Pr)P are taken from the literature [26].

\section{NiD(aryl)P and NiT(aryl)P Porphyrins}

In contrast to the essentially ruffled alkyl-substituted porphyrins, the macrocycle of the aryl-substituted porphyrins is displaced along both the sad and the ruf normal mode (see Figure 5). Displacements along higher frequency normal modes occur only for the diaryl-derivatives, particularly with a very small contribution of doming $(0.01 \AA)$. In the diaryl-substituted series, i.e. NiD(3-MeOPh)P, NiD(Ph)P and NiD(4-MePh)P, the displacement along ruf is $0.93-0.97 \AA$ and along sad $0.19-0.26 \AA$. For the tetraaryl substituted porphyrins, i.e. NiT(Ph)P and NiT(4-MeOPh)P, larger ruf displacements of 1.28 $1.35 \AA$ and much larger sad displacements of $0.75-1.08 \AA$ are observed. The increase of ruffling upon raising the number of meso-aryl substituents from two to four is similar to the above described meso-alkyl substituted counterparts, but the increased saddling is unprecedented, compared to, e.g., NiD(1-Et-Pr)P ( $\left.d_{\text {ruf }}=1.59 \AA, d_{\text {sad }}=0.09 \AA\right)$ and NiT(1-Et-Pr)P ( $\left.d_{\text {ruf }}=2.12 \AA, d_{\text {sad }}=0.09 \AA\right)$. The specific type of aryl-substituent significantly impacts oop distortions in tetraaryl substituted porphyrins. For example, the saddling in NiT(4-MeOPh)P ( $\left.d_{\text {ruf }}=1.28 \AA, d_{\text {sad }}=1.08 \AA\right)$ is much stronger than for $\operatorname{NiT}(\mathbf{P h}) \mathbf{P}\left(d_{\text {ruf }}=1.35 \AA, d_{\text {sad }}=0.75 \AA\right.$ ), while ruffling is slightly decreased.

In contrast to the dialkyl- and tetraalkyl-substituted porphyrins, the macrocycle of diaryl- and tetraarylsubstituted porphyrins is not only ruffled but shows additional contributions of saddling. The dihedral angle between the aryl-substituents and the porphyrin mean plane decreases with the number of aryl- 
substituents from $66^{\circ}$ for $\mathrm{NiD}(\mathrm{Ph}) \mathbf{P}$ to $61^{\circ}$ for $\mathrm{NiT}(\mathrm{Ph}) \mathbf{P}$. The stronger tilting of the substituents in the diaryl-substituted porphyrins is related to the extent of saddling, which increases from $d_{\text {sad }}=0.23 \AA$ for

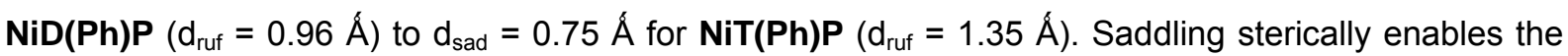
rotation of the aryl-substituents into the porphyrin plane and thus increases the energetically favorable overlap for the $\pi$-system of the peripheral aryl-substituents and the macrocycle [87]. This fact can be understood by comparing pure ruf and sad distortions: Upon saddling the two $\beta$-carbon atoms which are closest to the meso-carbon atom are displaced to opposite sides of the porphyrin mean plane while the meso-carbon atom stays in the porphyrin mean plane. Thus, the steric repulsion between the meso-aryl group and the closest $\beta$-carbon atoms is reduced. This, in turn, enables tilting of the originally perpendicular meso-aryl substituent into the porphyrin mean plane. On the other hand, the ruf distortion displaces the meso-substituents and both closest $\alpha$ - and $\beta$-carbon atoms to one side of the porphyrin mean plane. Titling of the meso-aryl group into the porphyrin plane is inhibited by the steric repulsion between the meso-aryl groups and the closest $\beta$-carbon atoms of the porphyrins. To graphically illustrate ruffling and saddling and the consequences for the orientation of the peripheral substituents Figure S1-2 in the Supporting Information compares the structures of NiD(Ph)P and NiT(Ph)P. A correlation between the degree of saddling and the dihedral angle between the arylsubstituents and the porphyrin mean plane was observed in X-ray crystallographic studies [92] and MM calculations [21]. It was concluded that a small dihedral angle requires a saddled conformer. Increasing the number of meso-aryl substituents raises the energy gain from $\pi$-conjugation, which allows to overcome the energy cost for a stronger saddling distortion, as observed for $\mathbf{N i D}(\mathbf{P h}) \mathbf{P}\left(\mathrm{d}_{\mathrm{sad}}\right.$ $=0.23 \AA \hat{)})$ and $\operatorname{NiT}(\mathbf{P h}) \mathbf{P}\left(\mathrm{d}_{\mathrm{sad}}=0.75 \hat{A}\right)$.

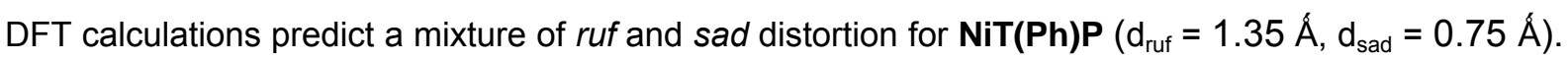
This is also observed in the crystal structure $\left(d_{\text {ruf }}=1.27 \AA d^{\prime} d_{\text {sad }}=0.26 \AA\right.$, see Figure 5) [93]. According to DFT, sad distortions are further increased for NiT(4-MeOPh)P to $d_{\text {sad }}=1.08 \AA$, while the ruf distortion is slightly decreased, which illustrates exemplarily how the substitution of the aryl-group influences the $\pi$-conjugation and can increase the driving force for saddling. The predicted increase (decrease) of saddling (ruffling) is also supported by the crystal structure of NiT(4-MeOPh)P ( $\mathrm{d}_{\mathrm{ruf}}=0.97 \AA \mathrm{A}_{\mathrm{sad}}=2.11 \AA \hat{\text { }}$ ) [94]. The correlation of porphyrin-core saddling and twisting of meso-aryl substituents was studied in detail for free-base porphyrins by DFT [87], where a similar effect was found, which is that substituents on the aryl groups tend to increase sad distortions.

Contrary to the DFT calculations, MM predict a purely ruf distortion for $\operatorname{NiD}(\mathrm{Ph}) \mathrm{P}\left(\mathrm{d}_{\mathrm{ruf}}=0.61 \AA \hat{\text { ) }}\right.$ [67] and NiT(Ph)P ( $d_{\text {ruf }}=1.48 \AA \hat{\text { ) }}$ (see Figure 5) [26,72]. In previous X-ray crystallographic studies [92] and MM calculations [21] it was assumed that the tilting of the aryl groups in metalloporphyrins, and thus saddling, is induced by crystal packing forces. According to the DFT calculation described here and prior DFT studies on NiT(Ph)P [83] both saddling and ruffling contribute to the non-planar distortion of NiD(aryl)P and NiT(aryl)P. This is also supported by Raman dispersion spectroscopy showing that NiT(Ph)P exhibits both sad and ruf distortions [88]. Thus, DFT structures for the NiD(aryl)P and NiT(aryl)P porphyrins revealing a mixture of ruf and sad distortion seem reasonable, 
while the force field used for MM calculations is not able to accurately describe the electronic effects of aryl-substituents on the conformation of the macrocycle.

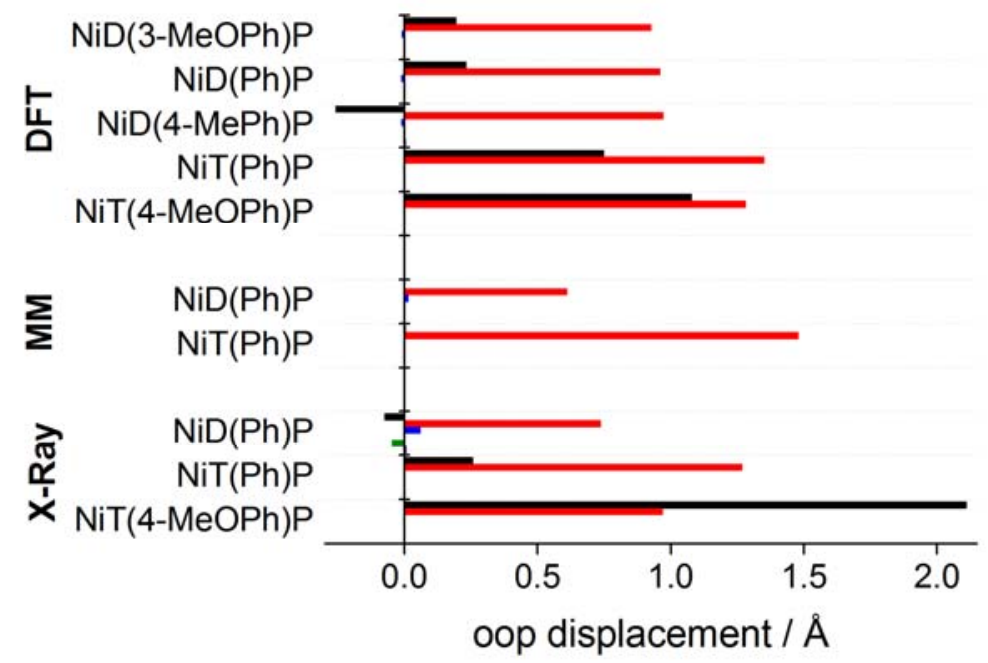

Figure 5: Displacements along the lowest-frequency oop normal coordinates for NiD(aryl)P and NiT(aryl)P porphyrins: sad (black), ruf (red), dom (blue), wav(x) (magenta), wav(y) (olive) and pro (navy). Structures are calculated with DFT (this study) and compared to reported MM calculations (values taken from literature, [26,67]) and to reported crystal structures (X-ray): NiT(Ph)P [93] and NiT(4-MeOPh)P [94]. The oop displacements for the crystal structure of NiD(Ph)P are taken from the literature [35].

\section{NiOET(aryl)P Porphyrins}

For the series of NiOET(aryl)P, i.e. NiOET(3-MeOPh)P, NiOET(Ph)P, NiOET(4-MeOPh)P and NiOET(4-Br-Ph)P, strong saddling distortions of $4.02-4.04 \AA$ are predicted by DFT (see Figure 6). Displacements of another type of symmetry are only observed along ruf. Ruffling is very small and decreases in the following order: NiOET(3-MeOPh)P (0.06 $\AA$ ), NiOET(Ph)P (0.03 $\AA$ ), NiOET(4-BrPh)P $(0.01 \AA)$ and NiOET(4-MeOPh)P $(0.00 \AA)$.

The NIOET(aryl)P investigated show large saddle distortions and exhibit almost no contribution of ruffling distortion. These sterically crowded porphyrins have peripheral substituents in all meso- and Bpositions and thus, steric repulsion between neighboring peripheral substitutions contributes additionally to the ones between the substituents and the porphyrin macrocycle. Apparently, this steric strain is most effectively minimized with a distortion along the saddling mode. The torsion angle between the phenyl-substituent and the porphyrin mean plane is $40^{\circ}$ for $\operatorname{NiOET}(\mathbf{P h}) \mathbf{P}$, i.e. much smaller compared to the $61^{\circ}$ for $\mathbf{N i T}(\mathbf{P h}) \mathbf{P}$. This smaller torsion angle is possible due to the strong sad displacement of $4.03 \AA$ as discussed for the NiD(aryl)P and NiT(aryl)P porphyrins in the previous section. DFT gives a Ni-N distance of $1.92 \AA$ in dichloromethane solution, which agrees with the value of $1.91 \pm 0.02 \AA$ [54] in tetrahydrofuran solution determined by extended X-ray absorption fine structure measurements. The calculated saddling distortion for $\operatorname{NiOET}(\mathbf{P h}) \mathbf{P}\left(\mathrm{d}_{\mathrm{sad}}=4.03 \AA \hat{)}\right)$ is consistent with the one from the crystal structure [54] $\left(d_{\mathrm{sad}}=3.81 \AA\right.$, see Figure 6) and with MM calculations $[54,64,95]$. 


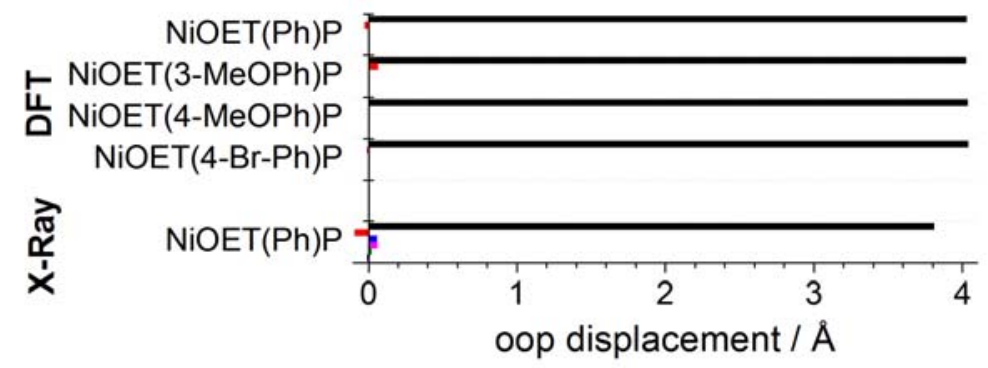

Figure 6: Displacements along the lowest-frequency oop normal coordinates for NiOE(aryl)P porphyrins: sad (black), ruf (red), dom (blue), wav(x) (magenta), wav(y) (olive) and pro (navy). Structures are calculated with DFT (this study) and compared to the reported crystal structure (X-ray) of NiOET(Ph)P [54].

\section{Resonance Raman Spectroscopy}

This section introduces resonance Raman spectroscopy as a spectroscopic technique to gain insight into the structure of the porphyrins in solution. As will be explained subsequently, the resonance Raman spectra of nickel(II) porphyrins contain structure-sensitive resonance Raman bands which shift to lower frequency upon an increase in the ruffling angle. Correlation of the frequency of these structure-sensitive resonance Raman bands and structural parameters have been reported in the literature $[24,26,31,63-65]$. These correlations are based purely on molecular mechanic calculations and crystal structures. Crucially, as discussed, oop deformations of nickel(II) porphyrins can be affected by crystal packing forces limiting the relevance of the crystal data for solution samples. Furthermore, the structural parameters calculated by MM may be affected by shortcomings of the MM calculations. Thus, the review will present updated correlations based on the structural parameters calculated at the DFT level of theory and will compare the derived correlation to reported ones based on MM calculations. DFT calculations are considered more reliable than MM calculations. Structures calculated by DFT are generally in better agreement with experimental results $[58,66,82]$ and experimental normal modes of nickel(II) porphyrins are more reliably reproduced reproduced by DFT than by MM $[58,83]$.

\section{Description of Resonance Raman Spectra}

The resonance Raman spectra of NiD(alkyl)P, NiT(alkyl)P, NiD(aryl)P and NiT(aryl)P porphyrins upon excitation at $413 \mathrm{~nm}$ show overall similarities in the high-frequency region between $1300-1700$ $\mathrm{cm}^{-1}$ (see Figures 7 and 8, for UV-vis absorption spectra see Figure S3). Two intense resonance Raman bands appear at approximately $1370\left(v_{4}\right)$ and $1570 \mathrm{~cm}^{-1}\left(v_{2}\right)$ and weaker bands at approximately $1460\left(v_{3}\right)$ and $1500 \mathrm{~cm}^{-1}\left(v_{28}\right)$. Additionally, a weak and broad resonance Raman band occurs at $1640 \mathrm{~cm}^{-1}\left(v_{10}\right)$ for the disubstituted porphyrins (see Figure 7). Bands $v_{4}, v_{3}$, and $v_{2}$ shift to lower frequencies upon increasing the sterically demand of the peripheral substituents, i.e. upon increasing the degree of non-planarity (see Figures 7 and 8). For this reason, the bands mentioned have been identified as structure-sensitive resonance Raman modes [24,26,31,63-65]. The resonance Raman bands of nickel(II) porphyrins can be assigned by analogy with, e.g., NiD(Ph)P [67] 
and NiT(Ph)P $[72,88]$ using the notation from the normal coordinate analysis as derived by Li et al. [96]. For the aryl-substituted porphyrins an aryl ip mode $v_{\Phi}$ contributes to the resonance Raman spectrum of NiD(aryl)P and NiT(aryl)P porphyrins in the region between $1600-1620 \mathrm{~cm}^{-1}[88,96]$. This mode can be distinguished from the porphyrin macrocycle ip mode $v_{10}$ by the quite different half-width and intensity: for Soret excitation $v_{10}$ is weak and very broad (see Figure 7) $[88,96]$.

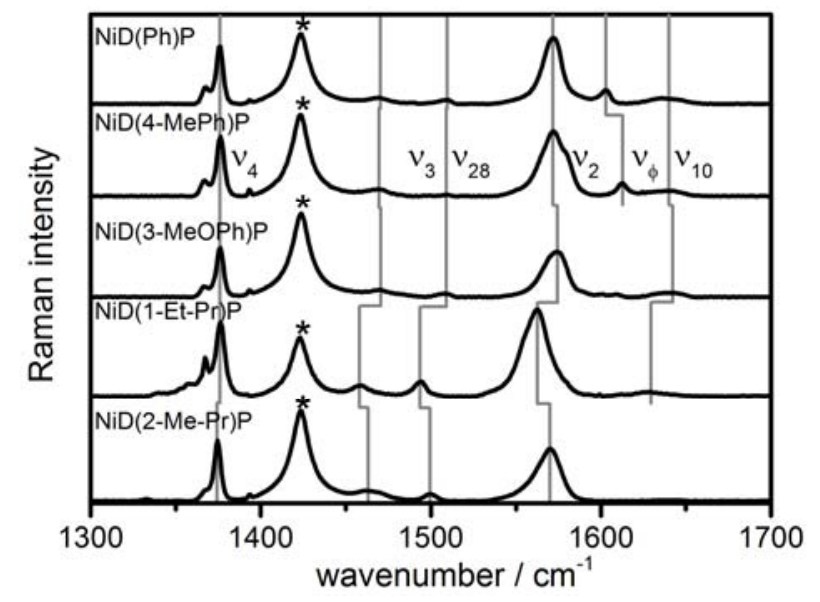

Figure 7: Resonance Raman spectra of NiD(aryl)P and NiD(alkyl) porphyrins in dichloromethane obtained upon $413 \mathrm{~nm}$ laser excitation. Structure-sensitive marker bands are indicated by grey bars. Solvent bands are marked by asterisks.

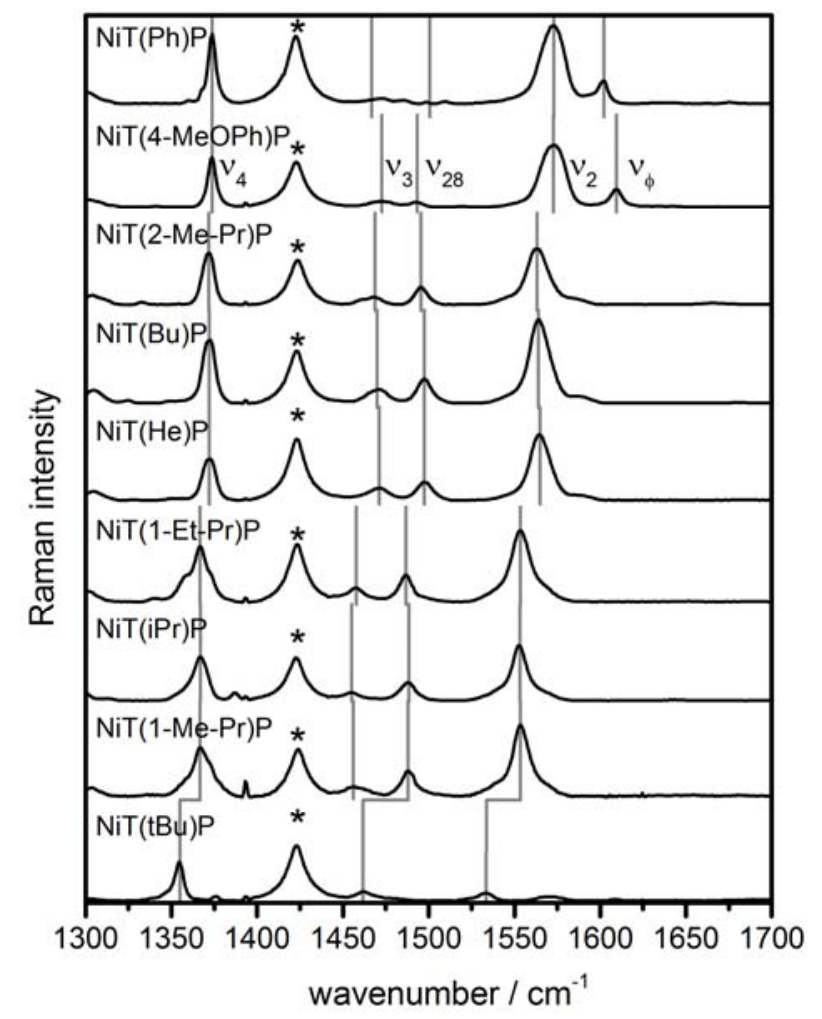

Figure 8: Resonance Raman spectra of NiT(alkyl)P and NiT(aryl)P porphyrins in dichloromethane obtained upon $413 \mathrm{~nm}$ laser excitation. Structure-sensitive marker bands are indicated by grey bars. Solvent bands are marked by asterisks. 
The resonance Raman spectra of the NiOET(aryl)P porphyrins (see Figure 9) are characterized by two intense structure-sensitive Raman marker bands $v_{4}$ and $v_{2}$ at approximately 1360 and $1560 \mathrm{~cm}^{-1}$, respectively [64] and additional strong bands in the 1400-1550 $\mathrm{cm}^{-1}$ region. The latter region is similar to that of NiOEP [64,97] and contains the intense mode $v_{3}$ [64]. The aryl group mode $v_{\Phi}$ appears at approximately $1600 \mathrm{~cm}^{-1}$ [64].

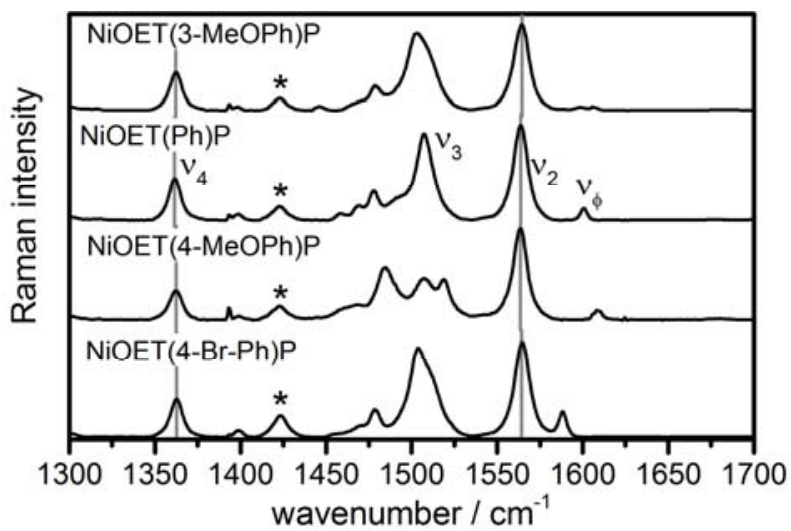

Figure 9: Resonance Raman spectra of NiOET(aryl)P porphyrins in dichloromethane obtained upon $413 \mathrm{~nm}$ laser excitation. Structure-sensitive marker bands are indicated by grey bars. Solvent bands are marked by asterisks.

The resonance Raman bands of nickel(II) porphyrins in the region below $1300 \mathrm{~cm}^{-1}$ strongly depend on the type of peripheral substituents (see Figure 10) and thus can serve as fingerprint to identify and distinguish porphyrins $[24,67]$. Furthermore, this region contains oop modes, which can be used to distinguish between different types of oop distortions $[69,70]$. 


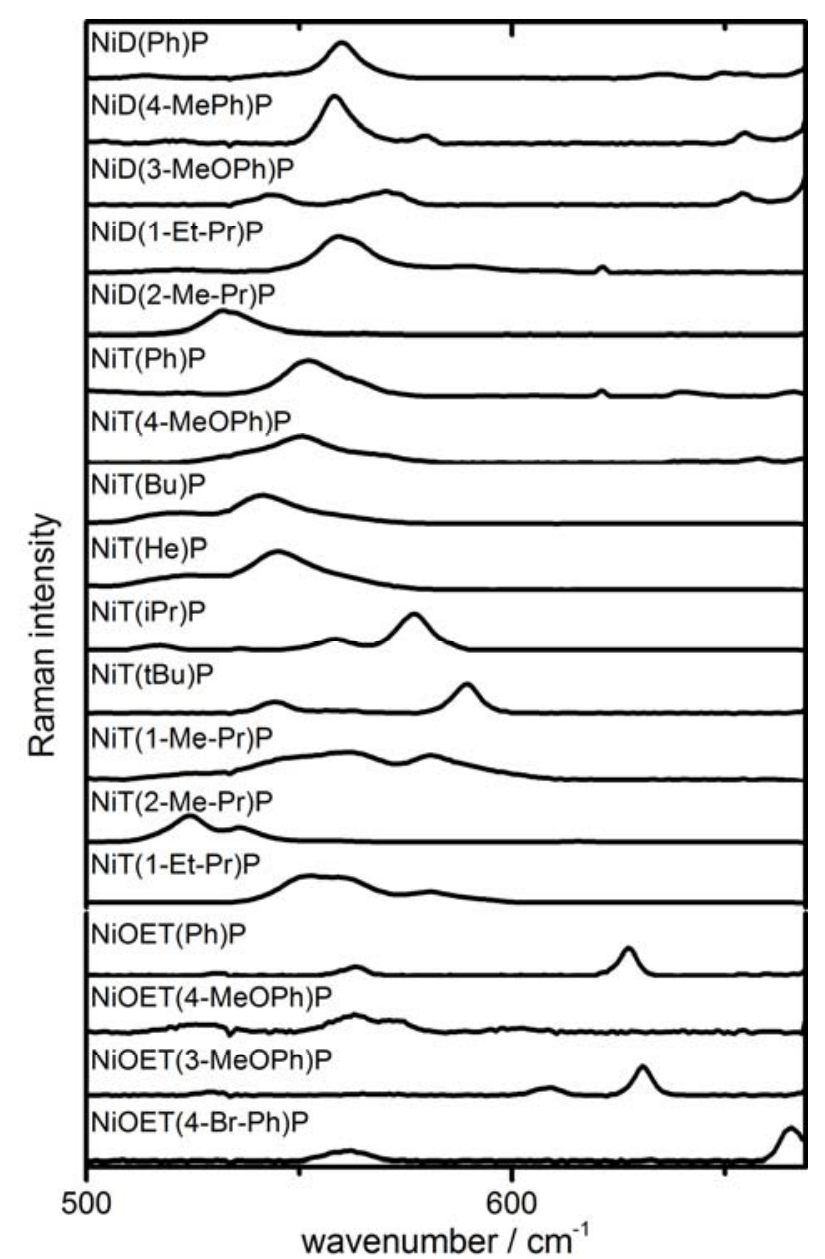

Figure 10: Resonance Raman spectra of the nickel(II) porphyrins investigated in dichloromethane obtained upon $413 \mathrm{~nm}$ laser excitation. The low-frequency region is presented. No solvent bands were observed within the presented frequency region.

\section{Shift of Resonance Raman Frequencies}

For the ruffled porphyrins, i.e. NiD(alkyl)P, NiT(alkyl)P, NiD(aryl)P and NiT(aryl)P, a shift of the resonance Raman bands to lower frequencies is observed for increasing degrees of ruffling $[24,26,63-$ 65]. For illustration, Figure 11A presents a plot of the frequency of the structure-sensitive resonance Raman bands $v_{4}, v_{3}$, and $v_{2}$ as a function of the calculated ruffling dihedral angle $\tau_{\text {ruf }}$ (torsion angle cis$\mathrm{C}_{\mathrm{a}}-\mathrm{N}-\mathrm{N}-\mathrm{C}_{\mathrm{a}}$, see Figure 1). Notably, NiOET(aryl)P porphyrins do not follow the trend of the ruffled nickel(II) porphyrins, due to the fact that NiOET(aryl)P porphyrins are essentially saddled $[54,64,95]$. However, the resonance Raman bands are also shifted to lower frequencies by saddling [64], e.g., as shown in Figure $11 \mathrm{~A}$, the $v_{2}$ mode for NiOET(aryl)P porphyrins (ruffling angles of less than $1.2^{\circ}$ ) is at approximately $1564 \mathrm{~cm}^{-1}$, which is the same as for the ruffled $\mathrm{NiT}(\mathrm{Bu}) \mathrm{P}$ (ruffling angle of $41^{\circ}$ ). 

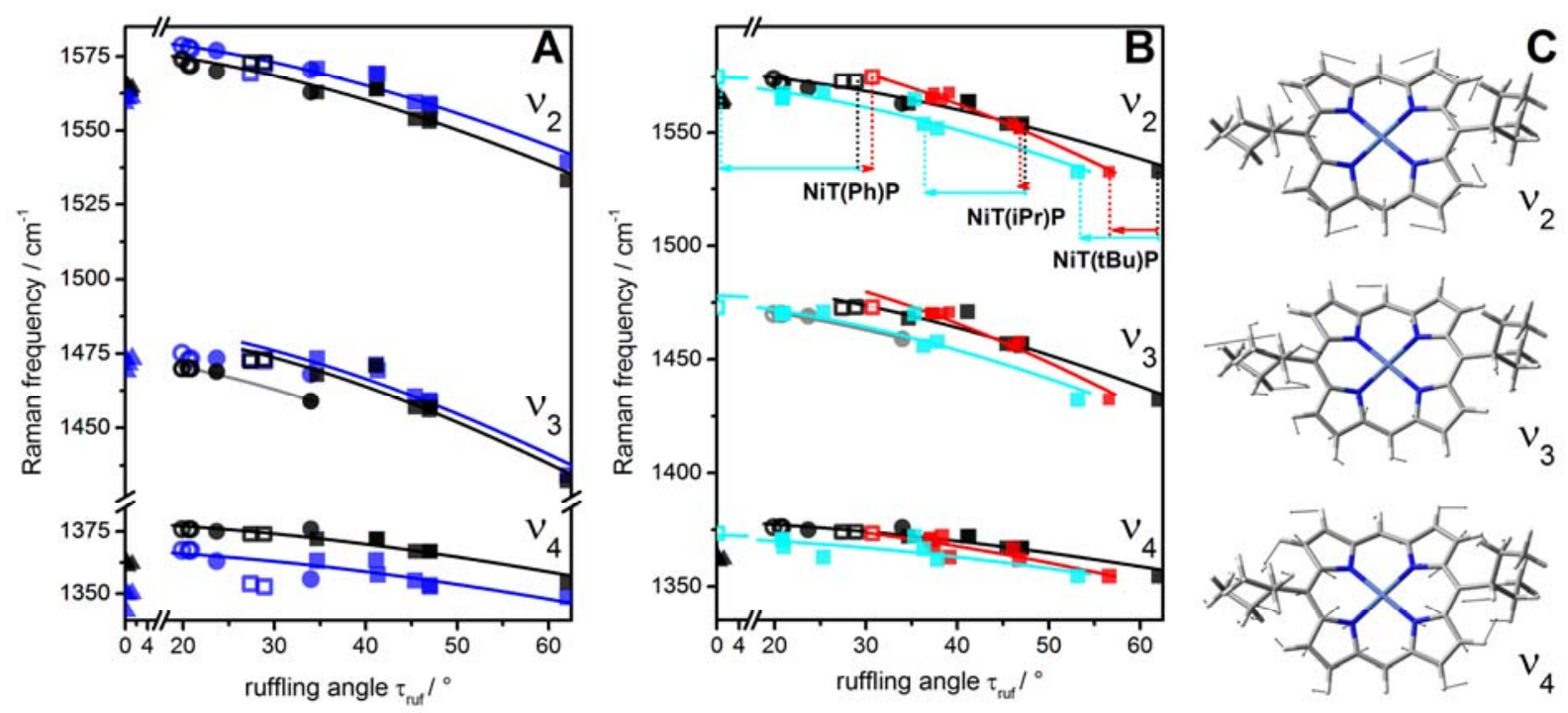

Figure 11: (A) Experimental (black) and calculated (blue) frequency of $v_{2}, v_{3}$ and $v_{4}$ for the NiD(alkyl)P (filled circles), NiD(aryl)P (open circles), NiT(alkyl)P (filled squares), NiT(aryl)P (open squares) and NiOET (aryl)P porphyrins (filled triangles) as a function of the calculated ruffling angle $\tau_{\text {ruf }}$ (Table 1 lists $\tau_{\text {ruf }}$ and experimental $v_{2}, v_{3}$ and $v_{4}$ ). Geometry and frequency calculations at the DFT level of theory. Fit of data using the functional form $v=A+B \cos \left(\tau_{\text {ruf }}\right)$ (solid lines, see text for details). Graph (B) compares the correlation of the experimental frequencies obtained and DFT calculated $\tau_{\text {ruf }}$ (black symbols and line, same as A) to correlations based on reported ruffling angles derived from MM calculations: experimental frequencies for a series of tetra-alkyl porphyrins (for details see text) [24] as function of $\tau_{\text {ruf }}$ calculated by MM using an empirical force (cyan symbols, values taken from Jentzen et al., [24]) and an improved empirical force field (red symbols, values taken from Song et al., [26]). Arrows indicate the deviation between the respective ruffling angles calculated by DFT and by the two force fields. (C) The displacement vectors of the respective normal modes are shown exemplarily for NiD(1-Et-Pr)P as derived from DFT calculations. 
The structure-sensitive resonance Raman bands $v_{4}, v_{3}$, and $v_{2}$ result from macrocycle ip vibrations [96]. The displacement vectors of $v_{4}, v_{3}$, and $v_{2}$ - derived from our DFT calculations - are exemplarily shown for NiD(1-Et-Pr)P in Figure 11C. Table S4 in the Supporting Information lists the displacement vectors of all investigated porphyrins. The frequency downshift of the ip vibrations $v_{4}, v_{3}$, and $v_{2}$ observed upon an increase in the ruffling angle (Figure $11 \mathrm{~A}$ ) is caused by a decreased $\pi$-conjugation within the porphyrin macrocycle [98]. ruf Distortions twist $p_{z}$ orbitals relative to each other and thus reduce the mutual orbital overlap. The orbital overlap has a cosine dependence on the dihedral angle between the individual $p_{z}$ orbitals. Consequently, a cosine dependence of the vibrational frequencies on the ruffling angle is expected [98].

Indeed, for the ruffled porphyrins, i.e. NiD(alkyl)P, NiT(alkyl)P, NiD(aryl)P and NiT(aryl)P (black symbols, Figure $11 \mathrm{~A})$, the vibrational frequency $v_{4}$ and $v_{2}$ exhibit a $\cos \left(\tau_{\text {ruf }}\right)$ dependence: the fit of the data using the equation $v=A+B \cos \left(\tau_{\text {ruf }}\right)$ yields good results for $v_{2}\left(A=1497(5) \mathrm{cm}^{-1}, B=82(6) \mathrm{cm}^{-1}, \mathrm{r}^{2}=\right.$ 0.93 , the number given in brackets refers to the uncertainty of the fit) and reasonable results for $v_{4}$ $\left(A=1338(3) \mathrm{cm}^{-1}, B=42(4) \mathrm{cm}^{-1} \mathrm{r}^{2}=0.90\right)$ (black lines, Figure 11A). An analogous fit to $v_{4}$ and $v_{2}$ cannot be successfully applied for $v_{3}$ due to the fact that the corresponding frequency is smaller for the disubstituted porphyrins than for the tetrasubstituted porphyrins with similar ruffling angles. The latter is apparent, e.g., for $\mathbf{N i D}(1-E t-P r) P\left(1459 \mathrm{~cm}^{-1}, \tau_{\text {ruf }}=34.0^{\circ}\right)$ and $\mathbf{N i T}(2-\mathrm{Me}-\mathbf{P r}) \mathbf{P}\left(1468 \mathrm{~cm}^{-1}, \tau_{\text {ruf }}=34.6^{\circ}\right)$. Therefore, the obtained frequencies of $v_{3}$ are fitted separately for the series of disubstituted $\left(A=1374(6) \mathrm{cm}^{-1}, B=102(7) \mathrm{cm}^{-1}, \mathrm{r}^{2}=0.98\right.$, grey line, Figure $\left.11 \mathrm{~A}\right)$ and tetrasubstituted porphyrins $\left(A=1390(8) \mathrm{cm}^{-1}, B=97(11) \mathrm{cm}^{-1}, r^{2}=0.92\right.$, black line, Figure 11A). The value for $B$, which describes the sensitivity of $v_{3}$ to an increasing ruffling angle, is similar for both series of porphyrins (disubstituted: $B=102(7) \mathrm{cm}^{-1}$, tetrasubstituted $B=97(11) \mathrm{cm}^{-1}$ ). Table 1 lists the experimentally obtained resonance Raman frequencies for $v_{4}, v_{3}$, and $v_{2}$, as well as the ruffling angles obtained from the calculated nickel(II) porphyrin structures.

Notably, the cosine dependence for $v_{4}, v_{3}$, and $v_{2}$ includes the values for the aryl-substituted porphyrins, which, contrary to the alkyl-substituted porphyrins, have geometries distorted by both ruf and sad. The strongest contributions of saddling to the overall distortion were predicted by DFT

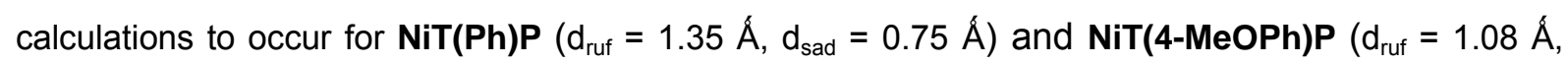
$d_{\text {sad }}=1.28 \AA$ ). Despite the additional contribution of saddling, these porphyrins do not significantly deviate from the cosine correlation (see black squares, Figure 11A); due to the fact that $v_{4}, v_{3}$, and $v_{2}$ are much less sensitive to saddling than to ruffling $[64,68]$.

The fact that $v_{2}$ is well described by the cosine function shows that the mode is solely determined by the ruffling angle and is independent of the number and type of meso-substituents. According to DFT calculations, the mode $v_{3}$ and $v_{4}$ are - contrary to $v_{2}$ - not pure macrocycle ip modes, but also involve the substituents (see Figure $11 \mathrm{C}$ and Table $\mathrm{S} 4$ in the Supporting Information). Thus, the frequencies of $v_{3}$ and $v_{4}$ are not solely determined by the macrocycle non-planarity but additionally by number and 
specific chemical nature of the substituent. This might explain the deviations from the expected cosine correlation.

Table 1: Selected structural parameters for the calculated structures: sad and ruf displacements as determined from normal-coordinate structural decomposition and ruffling angle $\tau_{\text {ruf. }}$ The experimental frequencies of selected resonance Raman bands were determined for the porphyrins in dichloromethane solution upon excitation at $413 \mathrm{~nm}$.

\begin{tabular}{|l|l|l|l|l|l|l|}
\hline & $\mathrm{d}_{\text {sad }} / \AA$ & $\mathrm{d}_{\text {ruf }} / \AA$ & $\tau_{\text {ruf }} /{ }^{\circ}$ & $v_{2} / \mathrm{cm}^{-1}$ & $v_{3} / \mathrm{cm}^{-1}$ & $v_{4} / \mathrm{cm}^{-1}$ \\
\hline NiD(3-MeOPh)P & 0.19 & 0.93 & 19.9 & 1574 & 1470 & 1376 \\
\hline NiD(Ph)P & 0.23 & 0.96 & 20.6 & 1572 & 1470 & 1376 \\
\hline NiD(4-MePh)P & 0.26 & 0.97 & 20.9 & 1572 & 1470 & 1376 \\
\hline NiD(2-Me-Pr)P & 0.05 & 1.10 & 23.7 & 1570 & 1462 & 1375 \\
\hline NiD(1-Et-Pr)P & 0.09 & 1.58 & 34.0 & 1563 & 1459 & 1376 \\
\hline NiT(Ph)P & 0.75 & 1.35 & 28.9 & 1573 & 1473 & 1374 \\
\hline NiT(4-MeOPh)P & 1.08 & 1.28 & 27.4 & 1573 & 1473 & 1374 \\
\hline NiT(2-Me-Pr)P & 0.26 & 1.62 & 34.7 & 1563 & & 1372 \\
\hline NiT(Bu)P & 0.00 & 1.74 & 41.1 & 1564 & 1471 & 1372 \\
\hline NiT(He)P & 0.00 & 1.74 & 41.3 & 1564 & 1472 & 1372 \\
\hline NiT(1-Et-Pr)P & 0.09 & 2.12 & 45.4 & 1554 & 1457 & 1367 \\
\hline NiT(iPr)P & 0.06 & 2.19 & 47.0 & 1553 & & 1367 \\
\hline NiT(1-Me-Pr)P & 0.12 & 2.20 & 47.1 & 1554 & & 1367 \\
\hline NiT(tBu)P & 0.14 & 2.90 & 62.1 & 1533 & 1432 & 1355 \\
\hline NiOET(3-MeOPh)P & 4.02 & 0.06 & 1.2 & 1564 & & 1362 \\
\hline NiOET(Ph)P & 4.03 & 0.03 & 0.5 & 1564 & & 1361 \\
\hline NiOET(4-MeOPh)P & 4.03 & 0.00 & 0.0 & 1564 & & 1362 \\
\hline NiOET(4-Br-Ph)P & 4.04 & 0.01 & 0.2 & 1564 & & 1363 \\
\hline
\end{tabular}

\section{Verification of Structures Calculated by DFT}

The correlation of vibrational frequencies frequency and ruffling angle described above depends on experimentally observed resonance Raman frequencies and the calculated ruffling angles. However, the structures predicted by DFT might be erroneous and, consequently, the thus determined correlations. In order to address the accuracy of the DFT structures, a subsequent vibrational analysis can be performed for each fully optimized porphyrin structure and the calculated frequencies can be compared to the experimentally observed frequencies. Figure $11 \mathrm{~A}$ shows that the calculated frequencies for $v_{2}, v_{3}$, and $v_{4}$ are in good agreement with the experimental ones.

Analogous to the experimentally obtained frequencies, the calculated frequencies of $v_{2}$ are fitted using the cosine function, which yields $A=1505(4) \mathrm{cm}^{-1}$ and $B=78(5) \mathrm{cm}^{-1}\left(r^{2}=0.95\right)$ (blue line, Figure 11A). The value for $B$ is in good agreement with the value determined from the experimental data $(B=83(6)$ $\mathrm{cm}^{-1}$ ). Thus, the structures in solution calculated by DFT and, more precisely, the increase in ruffling angle seem to be accurate. The value for $A$ derived from the DFT calculations $\left(A=1505(4) \mathrm{cm}^{-1}\right)$ 
deviates from the value determined using the experimentally observed frequencies $\left(1496(4) \mathrm{cm}^{-1}\right)$. However, A represents a constant offset of the resonance Raman frequencies with respect to structurally induced shifts of the Raman bands, which is apparently not exactly covered by the scaling factor of 0.98 applied for the DFT calculations $[77,99]$. The overall good agreement, which also holds true for the joint DFT-experimental analysis of $v_{3}\left(A=1394(8) \mathrm{cm}^{-1}, B=95(11) \mathrm{cm}^{-1} \mathrm{r}^{2}=0.90\right.$, fits only for tetrasubstituted porphyrins) and $v_{4}\left(A=1327(5) \mathrm{cm}^{-1}, B=42(6) \mathrm{cm}^{-1}, \mathrm{r}^{2}=0.79\right.$, values of NiT(4-MeOPh)P and $\operatorname{NiT}(\mathbf{P h}) \mathbf{P}$ excluded for fit; see Figure 11A), indicates that the calculated structures and the calculated ruffling angle are overall correctly predicted by DFT. Minor deviations for the aryl tetrasubstituted porphyrins NiT(4-MeOPh)P and NiT(Ph)P might be associated with the geometry of these porphyrins, which is distorted by both ruf and sad.

\section{Comparison to Molecular Mechanics}

In this section, the correlation between the experimental resonance Raman frequency of $v_{2}, v_{3}$, and $v_{4}$ and the DFT calculated ruffling angle is compared to the MM calculations reported in the literature. Jentzen et al. [24] (cyan symbols, Figure 11B) reported the experimental resonance Raman spectra for a series of tetraalkyl-meso-substituted nickel porphyrins NiT(alkyl)P and determined the porphyrin structures and ruffling angles by MM using an empirical force field [24]. The series of porphyrins studied by Jentzen et al. included NiT(iPr)P), NiT(tBu)P) and NiT(Ph)P, i.e. porphyrins which are also investigated here by DFT, as well as NiT(alkyl)P porphyrins with the following alkyl substituents: methyl, ethyl, propyl, pentyl, cyclopropyl, cyclohexyl. They measured the degree of non-planarity using the torsion angle $\varphi$ of the $N-C_{a}-C_{m}-C_{a}$ bond, which is about one half of the ruffling angle [24], and applied a quadratic equation for fitting (Raman frequency $v$ in $\mathrm{cm}^{-1}, v=A+B \varphi^{2}$ ). This quadratic equation represents a truncated Taylor polynomial approximating the cosine function at zero angle. Thus - for the observed ruffling angles smaller than $70^{\circ}$ - the proposed analysis is similar to the one applied here. Here, for sake of comparison, the calculated ruffling $\tau_{\text {ruf }}$ is considered and fits were obtained using the cosine-dependence $\left(v=A+B \cos \left(\tau_{\text {ruf }}\right)\right)$, which yields a reasonable fit for $v_{2}$ $\left(A=1475(10) \mathrm{cm}^{-1}, B=100(11) \mathrm{cm}^{-1}, r^{2}=0.90\right)$ (cyan line Figure 11B). Figure 11B also compares the resulting correlation for $v_{3}$ and $v_{4}$. Subsequently, solely $v_{2}$, which, as discussed, is less dependent on the specific nature of the substituents, is considered for the comparison of correlations based on DFT and MM.

The horizontal arrows in Figure 11B indicate that the ruffling angles for $\operatorname{NiT}(\mathrm{iPr}) \mathbf{P}, \mathbf{N i T}(\mathrm{tBu}) \mathbf{P}$, and $\operatorname{NiT}(\mathrm{Ph}) \mathrm{P}$ calculated with the original force filed used by Jentzen et al. [24] strongly deviate from the angle predicted the DFT calculations. This deviation becomes apparent for, e.g., NiT(Ph)P for which a planar structure was predicted by the original force field. However, these predictions are in contrast to both the experiments and the DFT calculations, according to which this porphyrin exists as a nonplanar structure in solution. Overall, the ruffling angle calculated with the original force field strongly underestimates the ruffling angle. Although the absolute ruffling angle is not predicted correctly, the B value derived from the cosine fit for $v_{2}\left(B=100(11) \mathrm{cm}^{-1}\right)$ is roughly similar to the DFT calculations $\left(B=82(6) \mathrm{cm}^{-1}\right)$, thus highlighting that the relative impact of an increasing sterically demand of 
substituents on the macrocycle non-planarity seems to be adequately covered irrespective of the method employed.

An improved empirical force field was applied by Song et al. [26] which gives significantly different ruffling angles compared to the work by Jentzen [24] (red symbols, Figure 11B). The improved force field predicts for NiT(Ph)P and for NiT(iPr)P ruffling angles, which are in good agreement with the DFT calculations. However, compared to DFT calculations, the ruffling angle for $\operatorname{NiT}(\mathbf{t B u}) \mathbf{P}$ is underestimated (see red arrows in Figure 11B). As a consequence, the cosine-dependence for $v_{2}$ $\left(A=1459(5) \mathrm{cm}^{-1}, B=135(7) \mathrm{cm}^{-1}, \mathrm{r}^{2}=0.98\right.$ ) gives a significantly higher value for $B$ than the DFT calculations $(B=82(6))$. To cross-validate the correlations, the specified cosine-dependence and fit parameters are used to predict the frequency of $v_{2}$ for a planar nickel porphyrin $\left(\tau_{\text {ruf }}=0^{\circ}\right)$, which yields $1594 \mathrm{~cm}^{-1}$ (improved force field) and $1579 \mathrm{~cm}^{-1}$ (DFT). By comparison of these values to the reported frequency for a planar NiT(Ph)P $\left(1578 \mathrm{~cm}^{-1}\right)$ [72], it appears that the cosine-dependence derived from the ruffling angles calculated by DFT is more accurate than the one derived from the improved force field (see Figure 11).

\section{Conclusion}

This tutorial review exemplarily summarizes various experimental and theoretical approaches to predict and correlate the structural distortions of nickel(II) porphyrins. Therefore, the structures for a series of 5,15-disubstituted and 5,10,15,20-tetrasubstituted, and 5,10,15,20-tetrasubstituted$2,3,7,8,12,13,17,18$-octaethyl nickel(II) porphyrins in dichloromethane were considered and evaluated by comparing the results from DFT and force-field calculations, resonance Raman spectroscopy as well as crystallographic studies. The systematic comparison of the various analytical methods highlights both the impact of crystal packing forces on the macrocycle distortions observed in crystal structures and the deviations between DFT and MM. For example, contrary to MM, DFT is able to correctly predict the mixed ruf and sad distortion of the di- or tetraaryl-substituted porphyrins, NiD(aryl)P and NiT(aryl)P.

For the meso-substituted porphyrins, a $\cos \left(\tau_{\text {ruf }}\right)$ correlation between the experimental frequency of the structure-sensitive resonance Raman modes $v_{2}, v_{3}$, and $v_{4}$ and the calculated ruffling angle $\tau_{\text {ruf }}$ is established, supporting that the origin of the frequency shift is a decreased m-overlap of the macrocycle. The most robust resonance Raman band to probe the ruffling angle of meso-substituted porphyrins is mode $v_{2}$. This vibrational mode is a pure macrocycle ip mode, which is almost not affected by the meso-substituents, while the ip modes $v_{3}$ and $v_{4}$ involve vibrations of the substituents and thus depend on the number and chemical nature of the substituent. The review demonstrates that the DFT calculated structures can be supported by the fact, that (i) the calculated vibrational frequencies for $v_{2}, v_{3}$ and $v_{4}$ are in good agreement with the experimentally observed resonance Raman frequencies and (ii) that the calculated vibrational frequencies resemble the experimentally obtained cosine correlation. Thus, this paper serves as a comparative and tutorial approach to access the structural distortions of metal porphyrins, which are ubiquitous molecular building blocks in biology, artificial photosynthesis and molecular electronics. 


\section{Materials and Methods}

\subsection{Synthesis}

Nickel(II) porphyrins were prepared via standard metallation of the respective free base porphyrins with nickel(II) acetylacetonate $\left(\mathrm{Ni}(\mathrm{acac})_{2}\right)$ and general experimental techniques were as reported before [100]. The following compounds were reported in the literature and gave satisfactory analytical data: NiD(Ph)P [67], NiD(3-MeOPh)P [101], NiD(4-MePh)P [102], NiD(2Me-Pr)P [101], NiD(1-Et-Pr)P [103], NiT(Ph)P [104], NiT(4-MeOPh)P [105], NiT(Bu)P [91], NiT(2-Me-Pr)P [91], NiT(iPr)P [24,91], NiT(1-Et-Pr)P [91], NiT(tBu)P [24,91], NiOET(Ph)P [64,95].

\section{[5,10,15,20-Tetrakis(n-hexyl)porphyrinato]nickel(II) $\quad$ NiT(He)P: $\quad 5,10,15,20$-Tetrakis $(n$ -} hexyl)porphyrin (200 mg, $0.309 \mathrm{mmol}$ ) was dissolved in toluene $(30 \mathrm{~mL})$ in a $100 \mathrm{~mL}$ RBF. The solution was heated to $120{ }^{\circ} \mathrm{C}$ before $\mathrm{Ni}(\mathrm{acac})_{2}(318 \mathrm{mg}, 1.236 \mathrm{mmol})$ was added. The reaction was stirred at this temperature $3 \mathrm{~h}$, monitoring via TLC control. The reaction was then cooled to rt and solvents were removed in vacuo. The crude residue was redissolved in $\mathrm{CH}_{2} \mathrm{Cl}_{2}$ and filtered through a short plug of silica gel using $\mathrm{CH}_{2} \mathrm{Cl}_{2}$ as eluent. The solvent was removed in vacuo and the residue was recrystallized from $\mathrm{CH}_{2} \mathrm{Cl}_{2} / \mathrm{MeOH}$ to give fine purple/red crystals $(210 \mathrm{mg}, 0.298 \mathrm{mmol}, 97 \%) . \mathrm{Mp}=$ 112-114 ${ }^{\circ} \mathrm{C} ; R_{f}\left(\mathrm{CH}_{2} \mathrm{Cl}_{2}:\right.$ hexane $\left.=2: 3, \mathrm{v} / \mathrm{v}\right): 0.85 ;{ }^{1} \mathrm{H} \mathrm{NMR}\left(400 \mathrm{MHz}, \mathrm{CDCl}_{3}\right): \delta=0.88$ (t, $J=7.2 \mathrm{~Hz}$, $\left.12 \mathrm{H}, \mathrm{CH}_{3}\right), 1.26-1.43\left(\mathrm{~m}, 16 \mathrm{H}, \mathrm{CH}_{2}\right), 1.51-1.58\left(\mathrm{~m}, 8 \mathrm{H}, \mathrm{CH}_{2}\right), 2.18-2.26\left(\mathrm{~m}, 8 \mathrm{H}, \mathrm{CH}_{2}\right), 4.47(\mathrm{t}, \mathrm{J}=8.1$ $\left.\mathrm{Hz}, 8 \mathrm{H}, \mathrm{CH}_{2}\right), 9.23 \mathrm{ppm}(\mathrm{s}, 8 \mathrm{H}, \beta-H) ;{ }^{13} \mathrm{C} \mathrm{NMR}\left(100 \mathrm{MHz}, \mathrm{CDCl}_{3}\right): \delta=14.1,22.6,30.0,31.8,33.9$, 37.2, 116.8, 129.6, 141.1 ppm; UV-vis $\left(\mathrm{CH}_{2} \mathrm{Cl}_{2}\right): \lambda_{\max }(\log \varepsilon)=419$ (5.37), $538 \mathrm{~nm}$ (4.17); HRMS (MALDI): $m / z=$ calcd. for $\mathrm{C}_{44} \mathrm{H}_{60} \mathrm{~N}_{4} \mathrm{Ni}: 702.4171$, found 702.4203 .

[5,10,15,20-Tetrakis(1-methylpropyl)porphyrinato]nickel(II) NiT(1-Me-Pr)P: 5,10,15,20-Tetrakis(1methylpropyl)porphyrin (150 mg, $0.280 \mathrm{mmol}$ ) was dissolved in toluene $(20 \mathrm{~mL})$ in a $100 \mathrm{~mL}$ RBF. The solution was heated to $120{ }^{\circ} \mathrm{C}$ before $\mathrm{Ni}(\mathrm{acac})_{2}(360 \mathrm{mg}, 1.402 \mathrm{mmol})$ was added. The reaction was stirred at this temperature $3 \mathrm{~h}$, monitoring via TLC control. The reaction was then cooled to rt and solvents were removed in vacuo. The crude residue was redissolved in $\mathrm{CH}_{2} \mathrm{Cl}_{2}$ and filtered through a short plug of silica gel using $\mathrm{CH}_{2} \mathrm{Cl}_{2}$ as eluent. The solvent was removed in vacuo and the residue was recrystallized from $\mathrm{CH}_{2} \mathrm{Cl}_{2} / \mathrm{MeOH}$ to give fine purple/red crystals (144 mg, $0.243 \mathrm{mmol}, 87 \%$ ). $\mathrm{Mp}=$ 283-285 ${ }^{\circ} \mathrm{C} ; R_{f}\left(\mathrm{CH}_{2} \mathrm{Cl}_{2}:\right.$ hexane $\left.=2: 3, \mathrm{v} / \mathrm{v}\right): 0.75 ;{ }^{1} \mathrm{H} \mathrm{NMR}\left(400 \mathrm{MHz}, \mathrm{CDCl}_{3}\right): \delta=0.91$ (t, $J=7.4 \mathrm{~Hz}$, $\left.12 \mathrm{H}, \mathrm{CH}_{3}\right), 2.18\left(\mathrm{~d}, J=7.3 \mathrm{~Hz}, 12 \mathrm{H}, \mathrm{CH}_{3}\right), 2.45-2.56\left(\mathrm{~m}, 8 \mathrm{H}, \mathrm{CH}_{2}\right), 4.36-4.45(\mathrm{~m}, 4 \mathrm{H}, \mathrm{CH}), 9.19 \mathrm{ppm}$ $(\mathrm{s}, 8 \mathrm{H}, \beta-H) ;{ }^{13} \mathrm{C}$ NMR $\left(100 \mathrm{MHz}, \mathrm{CDCl}_{3}\right): \delta=13.9,26.3,34.4,41.6,121.4,130.6,139.4 \mathrm{ppm}$; UV-vis $\left(\mathrm{CH}_{2} \mathrm{Cl}_{2}\right): \lambda_{\max }(\log \varepsilon)=423$ (5.16), 548 (4.03), $585 \mathrm{~nm}$ (3.41); HRMS (MALDI): $\mathrm{m} / \mathrm{z}=$ calcd. for $\mathrm{C}_{36} \mathrm{H}_{44} \mathrm{~N}_{4} \mathrm{Ni}: 590.2919$, found 590.2947 .

\section{5,10,15,20-Tetrakis(4-bromophenyl)-2,3,7,8,12,13,17,18-octaethylporphyrin}

$\mathrm{H}_{2} \mathrm{OET}(4-\mathrm{Br}-\mathrm{Ph}) \mathrm{P}$ : Dry $\mathrm{CH}_{2} \mathrm{Cl}_{2}$ (1L), 3,4-diethylprrole (1.23 g, $7 \mathrm{mmol}, 1$ eq.) and 4-bromobenzaldehyde (1.3 g, $7 \mathrm{mmol}, 1$ eq.) were placed in a $2 \mathrm{~L} \mathrm{RBF}$ and stirred for 10 minutes. $\mathrm{BF}_{3}{ }^{\bullet} \mathrm{Et}_{2} \mathrm{O}(0.08 \mathrm{~mL}, 0.7 \mathrm{mmol}, 0.1$ eq.) was added and left to stir for $18 \mathrm{~h}$ at room temperature. 4,5-Dichloro-3,6-dioxocyclohexa-1,4-diene-1,2dicarbonitrile (DDQ) $(1.589 \mathrm{~g}, 7 \mathrm{mmol}, 1$ eq.) was added and the solution was stirred for $1 \mathrm{~h}$. The reaction was quenched with triethylamine $(0.1 \mathrm{~mL}, 0.7 \mathrm{mmol}, 0.1$ eq. $)$. The solvent was removed in 
vacuo and the residue taken up in $\mathrm{CH}_{2} \mathrm{Cl}_{2}$. The mixture was ultra-sonicated for 2 min and then filtered through a plug of silica, washing with $1 \% \mathrm{MeOH}$ in $\mathrm{CH}_{2} \mathrm{Cl}_{2}$. The eluted porphyrin fractions were evaporated to dryness and purified with silica gel chromatography using hexane:EtOAc (4:6) and dried in vacuo to give green flakes (664 mg, $0.57 \mathrm{mmol}, 33 \%)$. $\mathrm{Mp}=278-280{ }^{\circ} \mathrm{C} ; R_{f}\left(\mathrm{CH}_{2} \mathrm{Cl}_{2}\right.$ :hexane $=2: 3$, $\mathrm{v} / \mathrm{v}): 0.77 ;{ }^{1} \mathrm{H} \operatorname{NMR}\left(400.2 \mathrm{MHz}, \mathrm{CDCl}_{3}\right): \delta=-2.1$ (s, $\left.2 \mathrm{H}, \mathrm{NH}\right), 0.5\left(\mathrm{br} \mathrm{s}, 24 \mathrm{H}, \mathrm{CH}_{2} \mathrm{CH}_{3}\right), 1.8-2.6(\mathrm{~m}$, $\left.16 \mathrm{H}, \mathrm{CH}_{2} \mathrm{CH}_{3}\right), 7.8(\mathrm{~d}, 8 \mathrm{H}, J=8.4 \mathrm{~Hz}, \mathrm{Ar}-H), 8.2 \mathrm{ppm}(\mathrm{d}, 8 \mathrm{H}, J=8.4 \mathrm{~Hz}, \mathrm{Ar}-\mathrm{H}) ;{ }^{13} \mathrm{C} \mathrm{NMR}(100.6 \mathrm{MHz}$, $\mathrm{CDCl}_{3}$ ): $\delta=16.8,19.4,116.8,123.0,130.3,139.4 \mathrm{ppm}$; HRMS (MALDI) $\mathrm{m} / \mathrm{z}\left[\mathrm{M}+\mathrm{H}^{+}\right.$calcd. for $\left[\mathrm{C}_{60} \mathrm{H}_{59} \mathrm{Br}_{4} \mathrm{~N}_{4}\right]:$ : 1151.1473, found 1151.1525.

\section{[5,10,15,20-Tetrakis(4-bromophenyl)-2,3,7,8,12,13,17,18-octaethylporphyrinato]nickel(II)}

NiOET(4-Br-Ph)P: 5,10,15,20-Tetrakis(4-bromophenyl)-2,3,7,8,12,13,17,18-octaethylporphyrin (100 $\mathrm{mg}, 0.09 \mathrm{mmol}, 1$ eq.) and $\mathrm{Ni}(\mathrm{acac})_{2}(111 \mathrm{mg}, 0.43 \mathrm{mmol}, 5$ eq.) were placed in a $25 \mathrm{~mL}$ Schleck tube and dissolved in toluene $(5 \mathrm{~mL})$. The solution was stirred at $120^{\circ} \mathrm{C}$ for 18 hours. The reaction was then cooled to rt and solvent was removed in vacuo. The crude residue was redissolved in $\mathrm{CH}_{2} \mathrm{Cl}_{2}$ and filtered through a short plug of silica gel using $\mathrm{CH}_{2} \mathrm{Cl}_{2}$ as eluent. The solvent was removed in vacuo and the residue was recrystallized from $\mathrm{CH}_{2} \mathrm{Cl}_{2} / \mathrm{MeOH}$ to give fine purple/red crystals (84 $\mathrm{mg}, 0.07$ mmol, $77 \%$ ). $\mathrm{Mp}=>300{ }^{\circ} \mathrm{C} ; R_{f}($ EtOAchexane $=1: 1, \mathrm{v} / \mathrm{v}): 0.77 ;{ }^{1} \mathrm{H} \mathrm{NMR}\left(400.2 \mathrm{MHz}, \mathrm{CDCl}_{3}\right): \delta=0.5$ (t, $24 \mathrm{H}, J=7.5 \mathrm{~Hz}, \mathrm{CH}_{2} \mathrm{CH}_{3}$ ), 2.0 (br s, 8H, $\mathrm{CH}_{2} \mathrm{CH}_{3}$ ), 2.5 (br s, $\left.8 \mathrm{H}, \mathrm{CH}_{2} \mathrm{CH}_{3}\right), 7.8(\mathrm{~d}, 8 \mathrm{H}, J=8.3 \mathrm{~Hz}$, Ar- $H$ ), 7.9 ppm (d, 8H, $J=8.3 \mathrm{~Hz}, \mathrm{Ar}-H) ;{ }^{13} \mathrm{C} \mathrm{NMR}\left(100.6 \mathrm{MHz}, \mathrm{CDCl}_{3}\right): \delta=17.0,19.7,116.0,122.8$, 130.3, 135.7, 138.8, 144.6, 145.5 ppm; UV-vis $\left(\mathrm{CH}_{2} \mathrm{Cl}_{2}\right): \lambda_{\max }(\log \varepsilon): 435$ (5.18), 555 (4.01), $591 \mathrm{~nm}$ (3.94); HRMS (MALDI) $\mathrm{m} / \mathrm{z}$ [M] ${ }^{+}$calcd. for $\left[\mathrm{C}_{60} \mathrm{H}_{56} \mathrm{Br}_{4} \mathrm{~N}_{4} \mathrm{Ni}\right]$ : 1206.0592 , found 1206.0629 .

\section{[2,3,7,8,12,13,17,18-Octaethyl-5,10,15,20-tetrakis(4-methoxyphenyl)porphyrinato]nickel(II)}

NiOET(4-MeO-Ph)P: Prepared following the procedure given for NiOET(4-Br-Ph)P. 2,3,7,8,12,13,17,18-Octaethyl-5,10,15,20-tetrakis(4-methoxyphenyl)porphyrin (100 mg, $0.1 \mathrm{mmol}$ ) and $\mathrm{Ni}(\text { acac })_{2}(77 \mathrm{mg}, 0.3 \mathrm{mmol})$ were placed in a $100 \mathrm{~mL}$ RBF and dissolved in toluene $(40 \mathrm{~mL})$. The solution was stirred at $120^{\circ} \mathrm{C}$ for 3 hours. The reaction was then cooled to rt and solvent was removed in vacuo. The crude residue was redissolved in $\mathrm{CH}_{2} \mathrm{Cl}_{2}$ and filtered through a short plug of silica gel using $\mathrm{CH}_{2} \mathrm{Cl}_{2}$ as eluent. The solvent was removed in vacuo and the residue was recrystallized from $\mathrm{CH}_{2} \mathrm{Cl}_{2} / \mathrm{MeOH}$ to give fine purple/red crystals $\left(52 \mathrm{mg}, 51 \mu \mathrm{mol}, 51 \%\right.$ ). $\mathrm{Mp}=>300{ }^{\circ} \mathrm{C} ; R_{f}$ $\left(\mathrm{CH}_{2} \mathrm{Cl}_{2}:\right.$ hexane $\left.=2: 3, \mathrm{v} / \mathrm{v}\right): 0.41 ;{ }^{1} \mathrm{H}$ NMR $\left(400 \mathrm{MHz}, \mathrm{CDCl}_{3}\right): \delta=0.5\left(\mathrm{t}, 24 \mathrm{H}, J=7.3 \mathrm{~Hz}, \mathrm{CH}_{2} \mathrm{CH}_{3}\right)$, 2.0-2.4 (m, 16H, $\left.\mathrm{CH}_{2} \mathrm{CH}_{3}\right), 4.0\left(\mathrm{~s}, 12 \mathrm{H}, \mathrm{OCH}_{3}\right), 7.1(\mathrm{~d}, 8 \mathrm{H}, J=8.6 \mathrm{~Hz}, \mathrm{Ar}-\mathrm{H}), 8.0 \mathrm{ppm}(\mathrm{d}, 8 \mathrm{H}, J=8.6$ $\mathrm{Hz}, \mathrm{Ar}-H) ;{ }^{13} \mathrm{C}$ NMR $\left(100 \mathrm{MHz}, \mathrm{CDCl}_{3}\right): \delta=17.1,19.6,55.5,112.4,116.5,133.0,135.2,145.0,145.3$, 159.7 ppm; UV-vis $\left(\mathrm{CH}_{2} \mathrm{Cl}_{2}\right): \lambda_{\max }(\log \varepsilon): 436$ (5.00), 554 (3.85), $588 \mathrm{~nm}$ (3.67); HRMS (MALDI) $\mathrm{m} / \mathrm{z}$ $[\mathrm{M}]^{+}$calcd. for $\left[\mathrm{C}_{64} \mathrm{H}_{68} \mathrm{~N}_{4} \mathrm{NiO}_{4}\right]:$ 1014.4594, found 1014.4615 .

\section{2,3,7,8,12,13,17,18-Octaethyl-5,10,15,20-tetrakis(3-methoxyphenyl)porphyrin}

$\mathrm{H}_{2} \mathrm{OET}$ (3-MeOPh)P: Dry $\mathrm{CH}_{2} \mathrm{Cl}_{2}$ (1L), 3,4-diethylprrole (1.23 mg, $0.1 \mathrm{mmol}$ ) and 3-methoxybenzaldehyde (1.49 g, 0.1 mmol) were placed in a $2 \mathrm{~L} \mathrm{RBF}$ and stirred for 10 minutes. $\mathrm{BF}_{3}{ }^{\circ} \mathrm{Et}_{2} \mathrm{O}(0.3 \mathrm{~mL}, 0.3 \mathrm{mmol})$ was added and left to stir for $18 \mathrm{~h}$ at room temperature. DDQ ( $4.54 \mathrm{~g}, 0.2 \mathrm{mmol})$ was added and the solution was stirred for $1 \mathrm{~h}$. The reaction was quenched with triethylamine $(6.7 \mathrm{~mL}, 0.3 \mathrm{mmol})$. The solvent was 
removed in vacuo and the residue taken up in $\mathrm{CH}_{2} \mathrm{Cl}_{2}$. The mixture was ultra-sonicated for 2 min and then filtered through a plug of silica, washing with $1 \% \mathrm{MeOH}$ in $\mathrm{CH}_{2} \mathrm{Cl}_{2}$. The eluted porphyrin fractions were evaporated to dryness and purified with silica gel chromatography using hexane:EtOAc (4:6) and dried in vacuo to give green flakes $(620 \mathrm{mg}, 0.6 \mathrm{mmol}, 25 \%)$. $\mathrm{Mp}=273-274{ }^{\circ} \mathrm{C} ; R_{f}\left(\mathrm{CH}_{2} \mathrm{Cl}_{2}\right.$ : $\mathrm{EtOAc}=$ 20:1, v/v): $0.25 ;{ }^{1} \mathrm{H}$ NMR (600.1 MHz, $\left.\mathrm{CDCl}_{3}: \mathrm{TFA}-d\right): \delta=-(0.3-0.2)(\mathrm{m}, 4 \mathrm{H}, \mathrm{NH}), 0.2(\mathrm{br} \mathrm{s}, 24 \mathrm{H}$, $\mathrm{CH}_{2} \mathrm{CH}_{3}$ ), 2.2 (br s, 8H, $\mathrm{CH}_{2} \mathrm{CH}_{3}$ ), 2.4 (br s, 8H, $\left.\mathrm{CH}_{2} \mathrm{CH}_{3}\right), 4.1\left(\mathrm{~s}, 12 \mathrm{H}, \mathrm{OCH}_{3}\right), 7.5(\mathrm{~d}, 4 \mathrm{H}, J=7.2 \mathrm{~Hz}$, Ar- $H$ ), $7.8 \mathrm{ppm}(\mathrm{t}, 4 \mathrm{H}, J=7.2 \mathrm{~Hz}, \operatorname{Ar}-H), 7.9-8.0(\mathrm{~m}, 4 \mathrm{H}, \mathrm{Ar}-H), 8.1 \mathrm{ppm}(\mathrm{m}, 4 \mathrm{H}, \mathrm{Ar}-H) ;{ }^{13} \mathrm{C} \mathrm{NMR}$ $\left(150.9 \mathrm{MHz}, \mathrm{CDCl}_{3}: \mathrm{TFA}-d\right): \delta=15.0,18.4,55.9,111.5,113.3,1152,116.6,1171,121.7,129.6$, 137.7, 139.7, $143.1 \mathrm{ppm}$; HRMS (MALDI) $\mathrm{m} / \mathrm{z}[\mathrm{M}+\mathrm{H}]^{+}$calcd. for $\left[\mathrm{C}_{64} \mathrm{H}_{71} \mathrm{~N}_{4} \mathrm{O}_{4}\right]$ : 959.5475 , found 959.5453.

\section{[2,3,7,8,12,13,17,18-Octaethyl-5,10,15,20-tetrakis(3-methoxyphenyl)porphyrinato]nickel(II)}

NiOET(3-MeO-Ph)P: $\quad$ 2,3,7,8,12,13,17,18-Octaethyl-5,10,15,20-tetrakis(3-methoxyphenyl)porphyrin $(100 \mathrm{mg}, 0.1 \mathrm{mmol})$ and $\mathrm{Ni}(\mathrm{acac})_{2}(77 \mathrm{mg}, 0.3 \mathrm{mmol})$ were placed in a $100 \mathrm{~mL}$ RBF and dissolved in toluene $(40 \mathrm{~mL})$. The solution was stirred at $120^{\circ} \mathrm{C}$ for 1.5 hours. The reaction was then cooled to rt and solvent was removed in vacuo. The residue was dissolved in $\mathrm{CH}_{2} \mathrm{Cl}_{2}$ and the mixture filtered through a plug of silica gel, eluting with $\mathrm{CH}_{2} \mathrm{Cl}_{2}$. The solvent was removed in vacuo and the residue was recrystallized from $\mathrm{CH}_{2} \mathrm{Cl}_{2} / \mathrm{MeOH}$ to give fine purple/red crystals $(94 \mathrm{mg}, 0.1 \mathrm{mmol}, 92 \%)$. $\mathrm{Mp}=$ $>300{ }^{\circ} \mathrm{C} ; R_{f}\left(\mathrm{CH}_{2} \mathrm{Cl}_{2}\right.$ :hexane = 2:3, v/v): 0.32; ${ }^{1} \mathrm{H}$ NMR $\left(400.2 \mathrm{MHz}, \mathrm{CDCl}_{3}\right): \delta=0.6(\mathrm{t}, 24 \mathrm{H}, J=7.2$ $\left.\mathrm{Hz}, \mathrm{CH}_{2} \mathrm{CH}_{3}\right), 2.3$ (bs, 16H, $\left.\mathrm{CH}_{2} \mathrm{CH}_{3}\right), 3.9-4.0\left(\mathrm{~m}, 12 \mathrm{H}, \mathrm{OCH}_{3}\right), 7.2(\mathrm{~m}, 4 \mathrm{H}, \mathrm{Ar}-\mathrm{H}), 7.5$ (bs, 4H, Ar-H), 7.6-7.7 ppm (m, 8H, Ar-H); $\left.{ }^{13} \mathrm{C} \mathrm{NMR} \mathrm{(100.6} \mathrm{MHz,} \mathrm{CDCl}_{3}\right): \delta=17.1,19.7,55.6,114.1,116.8,119.8$, 127.2, 127.9, 141.5, 144.3, 145.6, 158.3 ppm; UV-vis $\left(\mathrm{CH}_{2} \mathrm{Cl}_{2}\right): \lambda_{\max }(\log \varepsilon): 433$ (5.15), 552 (3.96), 589 nm (3.88) HRMS (MALDI) $m / z$ [M] $]^{+}$calcd. for $\left[\mathrm{C}_{64} \mathrm{H}_{68} \mathrm{~N}_{4} \mathrm{NiO}_{4}\right]:$ : 1014.4594 , found 1014.4577.

\subsection{Sample Preparation}

For the resonance Raman measurements, the samples were dissolved in dichloromethane and the concentration was adjusted to an absorbance of 0.3 at the excitation wavelength, i.e. $413 \mathrm{~nm}$, using a cuvette with $1 \mathrm{~mm}$ path length.

\subsection{Resonance Raman Spectroscopy}

Resonance Raman spectra were measured with a micro-Raman set-up (LabRam HR800, Horiba Jobin Yvon), consisting of an inverted microscope (Olympus IX71), a 600 lines per millimeter grating and a liquid-nitrogen-cooled CCD detector. The excitation light - delivered by a krypton ion laser (Coherent Innova 300C, $\lambda=413 \mathrm{~nm}$ ) - was focused by a microscope objective (Olympus 10×/NA 0.25 , RMS10X) into a cuvette containing the sample solution. The backscattered resonance Raman signals were collected by the same objective and detected without polarization filters. A rotating quartz cell was utilized as cuvette to prevent heating of the solution. UV/Vis-spectra were collected on Jasco V-670 spectrophotometer prior to and after each measurement to check the sample integrity. The Resonance Raman spectra presented here are baseline corrected with the software $R$ [106] using the package baseline wavelet [107] (parameter lambda $=500$ and signal-to-noise $=3$ ). Figure S7 in the Supporting Information gives an example for the original and baseline-corrected spectrum. 


\subsection{X-ray Crystallographic Data}

The structures of the nickel porphyrins investigated - derived from our DFT calculations - are compared to reported crystal structures which are taken from the Cambridge Structural Database (respective CSD entry given in parenthesis) [108] and analyzed by NSD: NiD(2-Me-Pr)P (QEBXUS) [89], NiTPP (ZZZUUC01) [93], NiT(4-MeOPh)P (OROJUB) [94], NiT(2-Me-Pr)P (DOWCAT) [91], NiT(1-Et-Pr)P (DOWDUO) [91], NiT(iPr)P (HETDAL) [90] and NiOETPP (SULCUX) [54]. Additionally, crystal structures of structurally similar nickel porphyrins were considered: [5,15-bis $(1,1-$ dimethylethyl)porphyrinato]nickel(II) (NiD(tBu)P, $\quad$ REFPOH) $\quad[67], \quad[5,15$-bis(1methylethyl)porphyrinato]nickel(II) (NiD(iPr)P, VAFQEY) [65], $\quad(5,10,15,20-$ tetrapentylporphyrinato)nickel(II) (NiT(Pe)P, FEZJOK01) [26]. Oop displacements for the crystal structure of $\mathbf{N i T}(\mathrm{Pr}) \mathbf{P}$ were taken from the literature [26].

\subsection{Computational Details}

All quantum chemical calculations have been performed using the Gaussian 09 program. Equilibrium structures and electronic structures of all 18 porphyrins were obtained at the DFT level of theory by means of a functional based on B3LYP [109,110], comprising $15 \%$ of exact-exchange, $58.5 \%$ of nonlocal B88 exchange and the LYP correlation, which is denoted B3LYP(15) [77,111-113]. The 10electron non-relativistic effective core potential MDF-10 [114] was used with its basis set for the nickel atom, that is, 3s, 3p, 3d and 4 s electrons are treated explicitly, whereas the two first inner shells are described by the core potential. For the ligand, the $6-31 G(d)$ double- $\zeta$ basis set [115] was employed. To correct for the lack of anharmonicity and for the approximate description of electron correlation, the harmonic frequencies were scaled by a factor of 0.98 [77,99]. Solvent effects (dichloromethane: $\varepsilon=$ 8.93) with respect to equilibrium structures and vibrational frequencies were taken into account by means of the integral equation formalism of the polarizable continuum model [116].

\subsection{Normal-Coordinate Structural Decomposition}

The oop and ip deformation present in the calculated, as well as the reported crystallographic structures were quantified by using the normal-coordinate structural decomposition (NSD) method by Shelnutt and coworkers [35]. The porphyrin structures were analyzed using the NSD program available online (Version 3.0) [86].

\section{Acknowledgements}

This research was supported by the Fonds der Chemischen Industrie (B.D., J.S.) and Science Foundation Ireland (SFI IvP 13/IA/1894, M.O.S.). 


\section{References}

[1] L.-L. Li, E.W.-G. Diau, Porphyrin-sensitized Solar Cells, Chem. Soc. Rev. 42 (2013) 291-304.

[2] S. Mathew, A. Yella, P. Gao, R. Humphry-Baker, B.F. Curchod, N. Ashari-Astani, I. Tavernelli, U. Rothlisberger, M.K. Nazeeruddin, M. Grätzel, Dye-sensitized Solar Cells with 13\% Efficiency Achieved through the Molecular Engineering of Porphyrin Sensitizers, Nat. Chem. 6 (2014) 242-247.

[3] Q. Yu, Y. Wang, Z. Yi, N. Zu, J. Zhang, M. Zhang, P. Wang, High-efficiency Dye-sensitized Solar Cells: The Influence of Lithium lons on Exciton Dissociation, Charge Recombination, and Surface States, ACS Nano. 4 (2010) 6032-6038.

[4] W. Zhang, W. Lai, R. Cao, Energy-related Small Molecule Activation Reactions: Oxygen Reduction and Hydrogen and Oxygen Evolution Reactions Catalyzed by Porphyrin-and Corrole-based Systems, Chem. Rev. 117 (2016) 3717-3797.

[5] D.K. Bediako, B.H. Solis, D.K. Dogutan, M.M. Roubelakis, A.G. Maher, C.H. Lee, M.B. Chambers, S. Hammes-Schiffer, D.G. Nocera, Role of Pendant Proton Relays and Proton-coupled Electron Transfer on the Hydrogen Evolution Reaction by Nickel Hangman Porphyrins, Proc. Natl. Acad. Sci. USA. 111 (2014) $15001-15006$.

[6] Y. Han, H. Fang, H. Jing, H. Sun, H. Lei, W. Lai, R. Cao, Singly Versus Doubly Reduced Nickel Porphyrins for Proton Reduction: Experimental and Theoretical Evidence for a Homolytic Hydrogenevolution Reaction, Angew. Chem. Int. Ed. 55 (2016) 5457-5462.

[7] F. Bedioui, N. Villeneuve, Electrochemical Nitric Oxide Sensors for Biological Samples-principle, Selected Examples and Applications, Electroanalysis. 15 (2003) 5-18.

[8] T. Malinski, Z. Taha, Nitric Oxide Release from a Single Cell Measured in Situ by a Porphyrinic-based Microsensor, Nature. 358 (1992) 676-678.

[9] M. Ethirajan, Y. Chen, P. Joshi, R.K. Pandey, The Role of Porphyrin Chemistry in Tumor Imaging and Photodynamic Therapy, Chem. Soc. Rev. 40 (2011) 340-362.

[10] L.B. Josefsen, R.W. Boyle, Unique Diagnostic and Therapeutic Roles of Porphyrins and Phthalocyanines in Photodynamic Therapy, Imaging and Theranostics, Theranostics. 2 (2012) 916-966.

[11] P. Agostinis, K. Berg, K.A. Cengel, T.H. Foster, A.W. Girotti, S.O. Gollnick, S.M. Hahn, M.R. Hamblin, A. Juzeniene, D. Kessel, M. Korbelik, J. Moan, P. Mroz, D. Nowis, J. Piette, B.C. Wilson, J. Golab, Photodynamic Therapy of Cancer: An Update, CA: Cancer J. Clin. 61 (2011) 250-281.

[12] R.M. Roat-Malone, Bioinorganic Chemistry: A Short Course, John Wiley \& Sons, New Jersey, 2007.

[13] T. Sakaki, Practical Application of Cytochrome P450, Biol. Pharm. Bull. 35 (2012) 844-849.

[14] A.W. Munro, H.M. Girvan, A.E. Mason, A.J. Dunford, K.J. McLean, What Makes a P450 Tick?, Trends Biochem. Sci. 38 (2013) 140-150.

[15] M. Gouterman, Spectra of Porphyrins, J. Mol. Spectrosc. 6 (1961) 138-163.

[16] K.M. Kadish, E.V. Caemelbecke, Electrochemistry of Metalloporphyrins in Nonaqueous Media, in: Encyclopedia of Electrochemistry, Wiley-VCH, 2007: pp. 175-228.

[17] M.O. Senge, Exercises in Molecular Gymnastics—bending, Stretching and Twisting Porphyrins, Chem. Commun. (2006) 243-256.

[18] J.A. Shelnutt, X.-Z. Song, J.-G. Ma, S.-L. Jia, W. Jentzen, C. J. Medforth, Nonplanar Porphyrins and Their Significance in Proteins, Chem. Soc. Rev. 27 (1998) 31-42.

[19] M.O. Senge, Highly Substituted Porphyrins, in: K.M. Kadish, K.M. Smith, R. Guilard (Eds.), The Porphyrin Handbook: Synthesis and Organic Chemistry, Academic Press, San Diego, 2000: pp. 239-347.

[20] M.O. Senge, S.A. MacGowan, J.M. O'Brien, Conformational Control of Cofactors in Nature - the Influence of Protein-induced Macrocycle Distortion on the Biological Function of Tetrapyrroles, Chem. Commun. 51 (2015) 17031-17063.

[21] O.Q. Munro, J.C. Bradley, R.D. Hancock, H.M. Marques, F. Marsicano, P.W. Wade, Molecular Mechanics Study of the Ruffling of Metalloporphyrins, J. Am. Chem. Soc. 114 (1992) 7218-7230.

[22] J. Hoard, Stereochemistry of Hemes and Other Metalloporphyrins, Science. 174 (1971) 1295-1302.

[23] K. Henrick, P.A. Tasker, L.F. Lindoy, The Specification of Bonding Cavities in Macrocyclic Ligands, Prog. Inorg. Chem. 33 (1985) 1-58.

[24] W. Jentzen, M. Simpson, J. Hobbs, X. Song, T. Ema, N. Nelson, C. Medforth, K. Smith, M. Veyrat, Ruffling in a Series of Nickel(ii) meso-tetrasubstituted Porphyrins As a Model for the Conserved Ruffling of the Heme of Cytochromes C, J. Am. Chem. Soc. 117 (1995) 11085-11097.

[25] B. Röder, M. Büchner, I. Rückmann, M.O. Senge, Correlation of Photophysical Parameters with Macrocycle Distortion in Porphyrins with Graded Degree of Saddle Distortion, Photochem. Photobiol. Sci. 9 (2010) 1152-1158.

[26] Y. Song, R.E. Haddad, S.-L. Jia, S. Hok, M.M. Olmstead, D.J. Nurco, N.E. Schore, J. Zhang, J.-G. Ma, K.M. Smith, S. Gazeau, J. Pécaut, J.-C. Marchon, C.J. Medforth, J.A. Shelnutt, Energetics and Structural Consequences of Axial Ligand Coordination in Nonplanar Nickel Porphyrins, J. Am. Chem. Soc. 127 (2005) 1179-1192.

[27] D.E. Bikiel, F. Forti, L. Boechi, M. Nardini, F.J. Luque, M.A. Marti, D.A. Estrin, Role of Heme Distortion on Oxygen Affinity in Heme Proteins: The Protoglobin Case, J. Phys. Chem. B. 114 (2010) 8536-8543.

[28] K.M. Kadish, M. Lin, E.V. Caemelbecke, G. De Stefano, C.J. Medforth, D.J. Nurco, N.Y. Nelson, B. Krattinger, C.M. Muzzi, L. Jaquinod, X. Yang, D.C. Shyr, K.M. Smith, J.A. Shelnutt, Influence of Electronic and Structural Effects on the Oxidative Behavior of Nickel Porphyrins, Inorg. Chem. 41 (2002) 6673-6687.

[29] K.M. Kadish, E. Van Caemelbecke, Electrochemistry of Porphyrins and Related Macrocycles, J. Solid State Electrochem. 7 (2003) 254-258. 
[30] J.S. Evans, R.L. Musselman, Red Shifting Due to Nonplanarity in Alkylporphyrins: A solid-state Polarized UV-vis Spectra and Zindo Calculations of Two Nickel(ii)octaethylporphyrins, Inorg. Chem. 43 (2004) 5613-5629.

[31] R.E. Haddad, S. Gazeau, J. Pécaut, J.-C. Marchon, C.J. Medforth, J.A. Shelnutt, Origin of the Red Shifts in the Optical Absorption Bands of Nonplanar Tetraalkylporphyrins, J. Am. Chem. Soc. 125 (2003) 12531268.

[32] C.M. Drain, S. Gentemann, J.A. Roberts, N.Y. Nelson, C.J. Medforth, S. Jia, M.C. Simpson, K.M. Smith, J. Fajer, J.A. Shelnutt, D. Holten, Picosecond to Microsecond Photodynamics of a Nonplanar Nickel Porphyrin: Solvent Dielectric and Temperature Effects, J. Am. Chem. Soc. 120 (1998) 3781-3791.

[33] M. Ravikanth, T. Chandrashekar, Nonplanar Porphyrins and Their Biological Relevance: Ground and Excited State Dynamics, in: Coordination Chemistry, Springer, 1995: pp. 105-188.

[34] W. Jentzen, J.-G. Ma, J.A. Shelnutt, Conservation of the Conformation of the Porphyrin Macrocycle in Hemoproteins, Biophys. J. 74 (1998) 753-763.

[35] W. Jentzen, X.-Z. Song, J.A. Shelnutt, Structural Characterization of Synthetic and Protein-bound Porphyrins in Terms of the Lowest-frequency Normal Coordinates of the Macrocycle, J. Phys. Chem. B. 101 (1997) 1684-1699.

[36] J.D. Hobbs, J.A. Shelnutt, Conserved Nonplanar Heme Distortions in Cytochromes c, J. Protein Chem. 14 (1995) 19-25. doi:10.1007/bf01902840.

[37] K.K. Anderson, J.D. Hobbs, L. Luo, K.D. Stanley, J. Quirke, J.A. Shelnutt, Planar Nonplanar Conformational Equilibrium in Metal Derivatives of Octaethylporphyrin and Meso-Nitrooctaethylporphyrin, J. Am. Chem. Soc. 115 (1993) 12346-12352.

[38] S.A. MacGowan, M.O. Senge, Conformational Control of Cofactors in Nature-functional Tetrapyrrole Conformations in the Photosynthetic Reaction Centers of Purple Bacteria, Chem. Commun. 47 (2011) 11621-11623.

[39] C. Olea Jr, J. Kuriyan, M.A. Marletta, Modulating Heme Redox Potential Through Protein-Induced Porphyrin Distortion, J. Am. Chem. Soc. 132 (2010) 12794-12795.

[40] Y. Imada, H. Nakamura, Y. Takano, Density Functional Study of Porphyrin Distortion Effects on Redox Potential of Heme, J. Comput. Chem. (2017).

[41] K.L. Bren, Going with the Electron Flow: Heme Electronic Structure and Electron Transfer in Cytochrome c, Isr. J. Chem. (2016).

[42] J.G. Kleingardner, K.L. Bren, Biological Significance and Applications of Heme c Proteins and Peptides, Accounts of chemical research. 48 (2015) 1845-1852.

[43] T.K. Shokhireva, R.E. Berry, E. Uno, C.A. Balfour, H. Zhang, F.A. Walker, Electrochemical and NMR Spectroscopic Studies of Distal Pocket Mutants of Nitrophorin 2: Stability, Structure, and Dynamics of Axial Ligand Complexes, Proc. Natl. Acad. Sci. USA. 100 (2003) 3778-3783.

[44] S. Neya, M. Suzuki, T. Hoshino, H. Ode, K. Imai, T. Komatsu, A. Ikezaki, M. Nakamura, Y. Furutani, H. Kandori, Molecular Insight into Intrinsic Heme Distortion in Ligand Binding in Hemoprotein, Biochemistry. 49 (2010) 5642-5650.

[45] C. Olea Jr, E.M. Boon, P. Pellicena, J. Kuriyan, M.A. Marletta, Probing the Function of Heme Distortion in the H-NOX Family, ACS Chem. Biol. 3 (2008) 703.

[46] D. Bednarczyk, O. Dym, V. Prabahar, Y. Peleg, D.H. Pike, D. Noy, Fine Tuning of Chlorophyll Spectra by Protein-induced Ring Deformation, Angew. Chem. Int. Ed. 55 (2016) 6901-6905.

[47] M. Zimmer, R.H. Crabtree, Bending of the Reduced Porphyrin of Factor F430 Can Accommodate a Trigonal-bipyramidal Geometry at Nickel: A Conformational Analysis of This Nickel-containing Tetrapyrrole, in Relation to Archaebacterial Methanogenesis, J. Am. Chem. Soc. 112 (1990) 1062-1066.

[48] L.R. Furenlid, M.W. Renner, J. Fajer, Exafs Studies of Nickel(II) and Nickel(I) Factor 430 M. Conformational Flexibility of the F430 Skeleton, J. Am. Chem. Soc. 112 (1990) 8987-8989.

[49] P.E. Cedervall, M. Dey, X. Li, R. Sarangi, B. Hedman, S.W. Ragsdale, C.M. Wilmot, Structural Analysis of a Ni-Methyl Species in Methyl-Coenzyme M Reductase from methanothermobacter Marburgensis, J. Am. Chem. Soc. 133 (2011) 5626-5628.

[50] A. Eschenmoser, Chemistry of Corphinoids, Ann. N.Y. Acad. Sci. 471 (1986) 108-129.

[51] C. Kratky, R. Waditschatka, C. Angst, J. Johansen, J. Plaquevent, J. Schreiber, A. Eschenmoser, The Saddle Conformation of Hydroporphinoid Nickel(II] Complexes: Structure, Origin, and Stereochemical Consequences, Chemlnform. 16 (1985) 1312-1338.

[52] R. Alden, M. Ondrias, J.A. Shelnutt, Influences of $\pi-\pi$ Complex Formation, Dimerization, and Binding to Hemoglobin on the Planarity of Nickel(II) Porphyrins, J. Am. Chem. Soc. 112 (1990) 691-697.

[53] J.A. Shelnutt, K. Alston, J.Y. Ho, N.T. Yu, T. Yamamoto, J.M. Rifkind, Four-and Five-Coordinate Species in Nickel-Reconstituted Hemoglobin and Myoglobin: Raman Identification of the Nickel-Histidine Stretching Mode, Biochemistry. 25 (1986) 620-627.

[54] K.M. Barkigia, M.W. Renner, L.R. Furenlid, C.J. Medforth, K.M. Smith, J. Fajer, Crystallographic and Exafs Studies of Conformationally Designed Nonplanar Nickel(II) Porphyrins, J. Am. Chem. Soc. 115 (1993) 3627-3635.

[55] M.O. Senge, M.W. Renner, W.W. Kallisch, J. Fajer, Molecular Structure of $(5,10,15,20$-tetrabutyl$2,3,7,8,12,13,17,18$-octaethylporphyrinato)nickel(II)_Correlation of Nonplanarity with Frontier Orbital Shifts, J. Chem. Soc., Dalton Trans. (2000) 381-385.

[56] R.L. Musselman, R.W. Larsen, B.M. Hoffman, Electronic Spectra of Porphyrins in the Solid State: Newly Observed Transitions, Collective and Structural Effects, and Protein-Mimicking Environments, Coord. Chem. Rev. 257 (2013) 369-380. 
[57] M. Renner, L. Furenlid, K. Barkigia, J. Fajer, Xafs and Crystallographic Studies of Ni(ii) Porphyrins in Single Crystals and Solution, J. Phys. IV France. 7 (1997) 661-662.

[58] P.M. Kozlowski, T.S. Rush, A.A. Jarzecki, M.Z. Zgierski, B. Chase, C. Piffat, B.-H. Ye, X.-Y. Li, P. Pulay, T.G. Spiro, DFT-SQM Force Field for Nickel Porphine: Intrinsic Ruffling, J. Phys. Chem. A. 103 (1999) 1357-1366.

[59] P. Dauber, A.T. Hagler, Crystal Packing, Hydrogen Bonding, and the Effect of Crystal Forces on Molecular Conformation, Acc. Chem. Res. 13 (1980) 105-112.

[60] M.O. Senge, H. Hope, K.M. Smith, Structure and Conformation of Photosynthetic Pigments and Related Compounds. Part 6. The First Crystal Structure of a Covalently-Linked Chlorin Dimer: 20,20'Ethylenebis(trans-2,3,7,8,12,13,17,18-octaethylchlorin), J. Chem. Soc., Perkin Trans. 2. (1993) 11-16.

[61] T.D. Brennan, W.R. Scheidt, J.A. Shelnutt, New Crystalline Phase of (octaethylporphinato)nickel(ii). Effects of $\Pi-\pi$ Interactions on Molecular Structure and Resonance Raman Spectra, J. Am. Chem. Soc. 110 (1988) 3919-3924.

[62] M. Wächtler, J. Guthmuller, L. González, B. Dietzek, Analysis and Characterization of Coordination Compounds by Resonance Raman Spectroscopy, Coord. Chem. Rev. 256 (2012) 1479-1508.

[63] J. Shelnutt, S. Majumder, L. Sparks, J. Hobbs, C. Medforth, M. Senge, K. Smith, M. Miura, L. Luo, J. Quirke, Resonance Raman Spectroscopy of Non-planar Nickel Porphyrins, J. Raman Spectrosc. 23 (1992) 523-529.

[64] J. Shelnutt, C. Medforth, M. Berber, K. Barkigia, K. Smith, Relationships between Structural Parameters and Raman Frequencies for Some Planar and Nonplanar Nickel(ii) Porphyrins, J. Am. Chem. Soc. 113 (1991) 4077-4087.

[65] X.-Z. Song, L. Jaquinod, W. Jentzen, D.J. Nurco, S.-L. Jia, R.G. Khoury, J.-G. Ma, C.J. Medforth, K.M. Smith, J.A. Shelnutt, Metal Dependence of the Contributions of Low-frequency Normal Coordinates to the Sterically Induced Distortions of Meso-dialkyl-substituted Porphyrins, Inorg. Chem. 37 (1998) 2009-2019.

[66] X.-Z. Song, W. Jentzen, L. Jaquinod, R.G. Khoury, C.J. Medforth, S.-L. Jia, J.-G. Ma, K.M. Smith, J.A. Shelnutt, Substituent-induced Perturbation Symmetries and Distortions of meso-tert-butylporphyrins, Inorg. Chem. 37 (1998) 2117-2128.

[67] X.-Z. Song, W. Jentzen, S.-L. Jia, L. Jaquinod, D.J. Nurco, C.J. Medforth, K.M. Smith, J.A. Shelnutt, Representation of Nonplanar Structures of Nickel(ii) 5,15-disubstituted Porphyrins in Terms of Displacements along the Lowest-frequency Normal Coordinates of the Macrocycle, J. Am. Chem. Soc. 118 (1996) 12975-12988.

[68] R. Franco, J.-G. Ma, Y. Lu, G.C. Ferreira, J.A. Shelnutt, Porphyrin Interactions with Wild-type and Mutant Mouse Ferrochelatase, Biochemistry. 39 (2000) 2517-2529.

[69] Q. Huang, C.J. Medforth, R. Schweitzer-Stenner, Nonplanar Heme Deformations and Excited State Displacements in Nickel Porphyrins Detected by Raman Spectroscopy at Soret Excitation, J. Phys. Chem. A. 109 (2005) 10493-10502.

[70] A.A. Jarzecki, T.G. Spiro, Porphyrin Distortion from Resonance Raman Intensities of Out-of-plane Modes: Computation and Modeling of $n$-methylmesoporphyrin, a Ferrochelatase Transition State Analog, J. Phys. Chem. A. 109 (2005) 421-430.

[71] W. Jentzen, E. Unger, G. Karvounis, J.A. Shelnutt, W. Dreybrodt, R. Schweitzer-Stenner, Conformational Properties of Nickel(ii) Octaethylporphyrin in Solution. 1. Resonance Excitation Profiles and Temperature Dependence of Structure-sensitive Raman Lines, J. Phys. Chem. 100 (1996) 14184-14191.

[72] W. Jentzen, E. Unger, X.-Z. Song, S.-L. Jia, I. Turowska-Tyrk, R. Schweitzer-Stenner, W. Dreybrodt, W.R. Scheidt, J.A. Shelnutt, Planar and Nonplanar Conformations of (mesotetraphenylporphinato)nickel(ii) in Solution As Inferred from Solution and Solid-state Raman Spectroscopy, J. Phys. Chem. A. 101 (1997) 5789-5798.

[73] R. Schweitzer-Stenner, Using Spectroscopic Tools to Probe Porphyrin Deformation and Porphyrinprotein Interactions, J. Porphyrins Phthalocyanines. 15 (2011) 312-337.

[74] S. Venkateshrao, J. Yin, A.A. Jarzecki, P.G. Schultz, T.G. Spiro, Porphyrin Distortion during Affinity Maturation of a Ferrochelatase Antibody, Monitored by Resonance Raman Spectroscopy, J. Am. Chem. Soc. 126 (2004) 16361-16367.

[75] T. Egawa, S.-R. Yeh, Structural and Functional Properties of Hemoglobins from Unicellular Organisms As Revealed by Resonance Raman Spectroscopy, J. Inorg. Biochem. 99 (2005) 72-96.

[76] C.M. Coyle, M. Puranik, H. Youn, S.B. Nielsen, R.D. Williams, R.L. Kerby, G.P. Roberts, T.G. Spiro, Activation Mechanism of the Co Sensor Cooa. Mutational and Resonance Raman Spectroscopic Studies, J. Biol. Chem. 278 (2003) 35384-35393.

[77] J. Schindler, S. Kupfer, L. Zedler, M. Wächtler, S. Gräfe, A.A. Ryan, M.O. Senge, B. Dietzek, Spectroelectrochemical Investigation of the One-electron Reduction of Nonplanar Nickel(ii) Porphyrins, ChemPhysChem. 17 (2016) 3480-3493.

[78] H.M. Marques, K.L. Brown, Molecular Mechanics and Molecular Dynamics Simulations of Porphyrins, Metalloporphyrins, Heme Proteins and Cobalt Corrinoids, Coord. Chem. Rev. 225 (2002) 123-158.

[79] X.Y. Li, R.S. Czernuszewicz, J.R. Kincaid, T.G. Spiro, Consistent Porphyrin Force Field. 3. Out-of-plane Modes in the Resonance Raman Spectra of Planar and Ruffled Nickel Octaethylporphyrin, J. Am. Chem. Soc. 111 (1989) 7012-7023.

[80] K. Prendergast, T.G. Spiro, Core Expansion, Ruffling, and Doming Effects on Metalloporphyrin Vibrational Frequencies, J. Am. Chem. Soc. 114 (1992) 3793-3801. 
[81] W. Jentzen, I. Turowska-Tyrk, W.R. Scheidt, J.A. Shelnutt, Planar Solid-state and Solution Structures of (porphinato)nickel(ii) As Determined by X-ray Diffraction and Resonance Raman Spectroscopy, Inorg. Chem. 35 (1996) 3559-3567.

[82] H.-H. Tsai, M.C. Simpson, Hbff-svd Force Field Treatment of Ni(ii) Porphine: Important Long Range Cross Terms, J. Phys. Chem. A. 107 (2003) 526-541.

[83] T.S. Rush, P.M. Kozlowski, C.A. Piffat, R. Kumble, M.Z. Zgierski, T.G. Spiro, Computational Modeling of Metalloporphyrin Structure and Vibrational Spectra: Porphyrin Ruffling in Nitpp, J. Phys. Chem. B. 104 (2000) 5020-5034.

[84] R. Kumble, T.S. Rush, M.E. Blackwood, P.M. Kozlowski, T.G. Spiro, Simulation of Non-condon Enhancement and Interference Effects in the Resonance Raman Intensities of Metalloporphyrins, J. Phys. Chem. B. 102 (1998) 7280-7286.

[85] M. Presselt, W. Dehaen, W. Maes, A. Klamt, T. Martínez, W.J.D. Beenken, M. Kruk, Quantum Chemical Insights into the Dependence of Porphyrin Basicity on the meso-aryl Substituents: Thermodynamics, Buckling, Reaction Sites and Molecular Flexibility, Phys. Chem. Chem. Phys. 17 (2015) 14096-14106.

[86] L. Sun, J.A. Shelnutt, NSD Program - Web Version 3: http://web.archive.org/web/20110828221532/http://jasheln.unm.edu/jasheln/content/nsd/NSDengine/start .htm, Nsd Program - Web Version 3, (2005).

[87] A. Rosa, G. Ricciardi, E.J. Baerends, Synergism of Porphyrin-core Saddling and Twisting of meso-aryl Substituents, J. Phys. Chem. A. 110 (2006) 5180-5190.

[88] E. Unger, W. Dreybrodt, R. Schweitzer-Stenner, Conformational Properties of Nickel(ii) mesotetraphenylporphyrin in Solution. Raman Dispersion Spectroscopy Reveals the Symmetry of Distortions for a Nonplanar Conformer, J. Phys. Chem. A. 101 (1997) 5997-6007.

[89] M.O. Senge, [5,15-bis(2-methylpropyl)porphyrinato]nickel(ii), Acta Cryst. E68 (2012) m1191-m1192.

[90] T. Ema, M.O. Senge, N.Y. Nelson, H. Ogoshi, K.M. Smith, 5,10,15,20-tetra-tert-butylporphyrin and Its Remarkable Reactivity in the 5- and 15-positions, Angew. Chem. Int. Ed. 33 (1994) 1879-1881.

[91] M.O. Senge, I. Bischoff, N.Y. Nelson, K.M. Smith, Synthesis, Reactivity and Structural Chemistry of 5,10,15,20-tetraalkylporphyrins, J. Porphyrins Phthalocyanines. 3 (1999) 99-116.

[92] W.R. Scheidt, Y.J. Lee, Recent Advances in the Stereochemistry of Metallotetrapyrroles, in: Metal Complexes with Tetrapyrrole Ligands I, Springer Berlin Heidelberg, 1987: pp. 1-70.

[93] A. Maclean, G. Foran, B. Kennedy, P. Turner, T. Hambley, Structural Characterization of Nickel(ii) Tetraphenylporphyrin, Aust. J. Chem. 49 (1996) 1273-1278.

[94] S.L. Tong, J. Zhang, Y. Yan, S. Hu, J. Yu, L. Yu, Supramolecular Assembly Based on a Series of mesotetrakis(p-methoxyphenyl)porphyrin Complexes, Solid State Sci. 13 (2011) 1320-1327.

[95] L. Sparks, C. Medforth, M. Park, J. Chamberlain, M. Ondrias, M. Senge, K. Smith, J. Shelnutt, Metal Dependence of the Nonplanar Distortion of Octaalkyltetraphenylporphyrins, J. Am. Chem. Soc. 115 (1993) 581-592.

[96] X.Y. Li, R.S. Czernuszewicz, J.R. Kincaid, Y.O. Su, T.G. Spiro, Consistent Porphyrin Force Field. 1. Normal-mode Analysis for Nickel Porphine and Nickel Tetraphenylporphine from Resonance Raman and Infrared Spectra and Isotope Shifts, J. Phys. Chem. 94 (1990) 31-47.

[97] X.Y. Li, R.S. Czernuszewicz, J.R. Kincaid, P. Stein, T.G. Spiro, Consistent Porphyrin Force Field. 2. Nickel Octaethylporphyrin Skeletal and Substituent Mode Assignments from ${ }^{15} \mathrm{~N}$, Meso- $\mathrm{d}_{4}$, and Methylene-d 16 Raman and Infrared Isotope Shifts, J. Phys. Chem. 94 (1990) 47-61.

[98] H.-H. Tsai, M.C. Simpson, Isolated Impact of Ruffling on the Vibrational Spectrum of Ni Porphyrins. Diagnosing Out-of-plane Distortions, J. Phys. Chem. A. 108 (2004) 1224-1232.

[99] J.P. Merrick, D. Moran, L. Radom, An Evaluation of Harmonic Vibrational Frequency Scale Factors, J. Phys. Chem. A. 111 (2007) 11683-11700.

[100] A. Ryan, A. Gehrold, R. Perusitti, M. Pintea, M. Fazekas, O.B. Locos, F. Blaikie, M.O. Senge, Porphyrin Dimers and Arrays, Eur. J. Org. Chem. (2011) 5817-5844.

[101] A. Wiehe, Y.M. Shaker, J.C. Brandt, S. Mebs, M.O. Senge, Lead Structures for Applications in Photodynamic Therapy. Part 1: Synthesis and Variation of $m$-thpc (temoporfin) Related Amphiphilic $\mathrm{A}_{2} \mathrm{bc}-$ type Porphyrins, Tetrahedron. 61 (2005) 5535-5564.

[102] X.-Q. Lu, Y. Guo, Q.-Y. Chen, Efficient Synthesis of meso-meso-linked Diporphyrins by Nickel(0)mediated Ullmann Homocoupling, Synlett. (2011) 77-80.

[103] S. Plunkett, K. Dahms, M.O. Senge, Synthesis and Reactivity of Allenylporphyrins, Eur. J. Org. Chem. 8 (2013) 1566-1579.

[104] A.D. Adler, F.R. Longo, F. Kampas, J. Kim, On the Preparation of Metalloporphyrins, J. Inorg. Nucl. Chem. 32 (1970) 2443-2445.

[105] D.W. Thomas, A.E. Martell, Metal Chelates of Tetraphenylporphine and of Some p-substituted Derivatives, J. Am. Chem. Soc. 81 (1959) 5111-5119.

[106] R: A Language and Environment for Statistical Computing, R Foundation for Statistical Computing, Vienna, Austria, 2015. https://www.R-project.org.

[107] Z.-M. Zhang, S. Chen, Y.-Z. Liang, Z.-X. Liu, Q.-M. Zhang, L.-X. Ding, F. Ye, H. Zhou, An Intelligent Background-correction Algorithm for Highly Fluorescent Samples in Raman Spectroscopy, J. Raman Spectrosc. 41 (2010) 659-669.

[108] C.R. Groom, I.J. Bruno, M.P. Lightfoot, S.C. Ward, The Cambridge Structural Database, Acta Cryst. B72 (2016) 171-179.

[109] A.D. Becke, Density-Functional Thermochemistry. III. The Role of Exact Exchange, J. Chem. Phys. 98 (1993) 5648-5652. 
[110] C. Lee, W. Yang, R.G. Parr, Development of the Colle-Salvetti Correlation-Energy Formula into a Functional of the Electron Density, Phys. Rev. B. 37 (1988) 785-789.

[111] S. Kupfer, L. Zedler, J. Guthmuller, S. Bode, M.D. Hager, U.S. Schubert, J. Popp, S. Gräfe, B. Dietzek, Self-Healing Mechanism of Metallopolymers Investigated by QM/MM Simulations and Raman Spectroscopy, Phys. Chem. Chem. Phys. 16 (2014) 12422-12432.

[112] M. Reiher, O. Salomon, B.A. Hess, Reparameterization of Hybrid Functionals Based on Energy Differences of States of Different Multiplicity, Theor. Chem. Acc. 107 (2001) 48-55.

[113] O. Salomon, M. Reiher, B.A. Hess, Assertion and Validation of the Performance of the B3lyp Functional for the First Transition Metal Row and the G2 Test Set, J. Chem. Phys. 117 (2002) 4729-4737.

[114] M. Dolg, U. Wedig, H. Stoll, H. Preuss, Ab initio Pseudopotential Study of the First Row Transition Metal Monoxides and Iron Monohydride, J. Chem. Phys. 86 (1987) 2123-2131.

[115] P.C. Hariharan, J.A. Pople, The Influence of Polarization Functions on Molecular Orbital Hydrogenation Energies, Theor. Chim. Acta. 28 (1973) 213-222.

[116] B. Mennucci, C. Cappelli, C.A. Guido, R. Cammi, J. Tomasi, Structures and Properties of Electronically Excited Chromophores in Solution from the Polarizable Continuum Model Coupled to the TimeDependent Density Functional Theory, J. Phys. Chem. A. 113 (2009) 3009-3020. 